
15 Corresponding author: Nick Schneider (nick.schneider@lasp.colorado.edu)

\section{Imaging of Martian circulation patterns and atmospheric tides through MAVEN/IUVS nightglow observations} Stiepen $^{3}$, J. Deighan ${ }^{1}$, A. I. F. Stewart ${ }^{1}$, F. Forget ${ }^{4}$, F. Lefèvre ${ }^{5}$, S.W. Bougher ${ }^{6}$

${ }^{1}$ Laboratory for Atmospheric and Space Physics, Boulder, Colorado, United States

${ }^{2}$ Instituto de Astrofísica de Andalucía-CSIC, Granada, Spain

${ }^{3}$ Laboratoire de Physique Atmosphérique et Planétaire, STAR Institute, Université de Liège, Belgium

${ }^{4}$ Laboratoire de Météorologie Dynamique (LMD), Paris, France Saclay, Sorbonne Université, CNRS, Paris, France

\section{Key Points:} which reveals the effects of global-scale winds and waves in the upper atmosphere. season and pinpoint an unusually bright spot on Mars' nightside. and allows an examination of the underlying physical causes.

N. M. Schneider ${ }^{1}$, Z. Milby ${ }^{1}$, S. K. Jain ${ }^{1}$, F. González-Galindo ${ }^{2}$, E. Royer ${ }^{1}$, J.-C. Gérard ${ }^{3}$, A.

${ }^{5}$ Laboratoire Atmosphères, Milieux, Observations Spatiales (LATMOS), UVSQ Université Paris-

${ }^{6}$ Climate and Space Sciences and Engineering Department, University of Michigan, Ann Arbor,

- The MAVEN spacecraft orbiting Mars has obtained a new type of nightside imaging data

- Ultraviolet nightglow emissions confirm the expected change of circulation patterns with

- A Mars General Circulation Model successfully matches many of the observed features 


\section{Abstract}

We report results from a study of two consecutive Martian years of imaging observations of nitric oxide ultraviolet nightglow by the Imaging Ultraviolet Spectrograph (IUVS) on the Mars Atmosphere and Volatile Evolution (MAVEN) mission spacecraft. The emission arises from recombination of $\mathrm{N}$ and $\mathrm{O}$ atoms in Mars' nightside mesosphere. The brightness traces the reaction rate as opposed to the abundance of constituents, revealing where circulation patterns concentrate $\mathrm{N}$ and $\mathrm{O}$ and enhance recombination. Emissions are brightest around the winter poles, with equatorial regions brightening around the equinoxes. These changes offer clear evidence of circulation patterns transitioning from a single cross-equatorial cell operating during solstice periods to more symmetric equator-to-poles circulation around the equinoxes. Prominent atmospheric tides intensify the emissions at different longitudes, latitude ranges and seasons. We find a strong eastward-propagating diurnal tide (DE2) near the equator during the equinoxes, with a remarkably bright spot narrowly confined near $\left(0^{\circ}, 0^{\circ}\right)$. Wave features at the opposite winter poles are dissimilar, reflecting different circulation patterns at perihelion versus aphelion. LMD-MGCM simulations agree with the patterns of most observed phenomena, confirming that the model captures the dominant physical processes. At the south winter pole, however, the model fails to match a strong wave-1 spiral feature. Observed brightnesses exceed model predictions by a factor of 1.9 globally, probably due to an underestimation of the dayside production of $\mathrm{N}$ and $\mathrm{O}$ atoms. Further study of discrepancies between the model and observations offer opportunities to improve our understanding of chemical and transport processes controlling the emission.

\section{Plain Language Summary}

The MAVEN spacecraft orbiting Mars has obtained a new type of imaging data which reveals the effects of global-scale winds and waves in the upper atmosphere. Ultraviolet emissions confirm the expected change of wind patterns with season, and pinpoint an unusually bright spot on Mars' nightside. Computer model runs successfully match many of the observed features, and allow an examination of the underlying physical causes. Differences between the model and observations offer insights on how to improve the model.

\section{Introduction}

The structure, composition and dynamics of the upper atmosphere of Mars are controlled by its interactions with solar radiation and the lower atmosphere (e.g., Bougher et al., 2015, 2017). Nitric oxide nightglow is a good remote tracer of these properties. This emission was first observed at Mars with the Spectroscopy for Investigation of Characteristics of the Atmosphere of Mars (SPICAM) spectrograph (Bertaux et al., 2005, 2006) on board the ESA Mars Express spacecraft and more recently with the Imaging Ultraviolet Spectrograph (IUVS) (McClintock et al., 2015, Stiepen et al., 2017) on board NASA's Mars Atmosphere and Volatile Evolution (MAVEN) spacecraft (Jakosky et al., 2015). Although nightglow measurements were not part of the MAVEN mission requirements, observations have proven to be straightforward and valuable. These nightglow NO emissions are not to be confused with dayside NO emissions (Stevens et al. 2019) which originate through a different physical process.

Nitric oxide ultraviolet nightglow reveals the recombination of $\mathrm{N}$ and $\mathrm{O}$ atoms on Mars' nightside through the reaction 


$$
\mathrm{N}\left({ }^{4} \mathrm{~S}\right)+\mathrm{O}\left({ }^{3} \mathrm{P}\right) \rightarrow \mathrm{NO}\left(\mathrm{C}^{2} \Pi\right)
$$

which leaves the molecule in an excited state that subsequently radiates. The observed brightness therefore traces the reaction rate as opposed to the abundance any specific constituent, revealing where dynamics, chemistry, and other factors enhance recombination. In essence, nightglow traces how dynamical processes create compositional differences in atomic species on Mars nightside. The reaction is essentially fueled by solar extreme ultraviolet radiation which photodissociates $\mathrm{CO}_{2}$ and $\mathrm{N}_{2}$ molecules in the dayside thermosphere, leaving the atomic fragments to be transported by global circulation patterns. Photoelectron impact on these molecules can also produce $\mathrm{O}\left({ }^{3} \mathrm{P}\right)$ and $\mathrm{N}\left({ }^{4} \mathrm{~S}\right)$ ground state atoms and lead to nightglow.

Conditions around the solstices give a clear example. Global circulation is strong, so thermospheric winds carry $\mathrm{N}$ and $\mathrm{O}$ atoms towards the dark winter pole, where they descend into the mesosphere. As densities increase downward into the mesopshere, $\mathrm{O}\left({ }^{3} \mathrm{P}\right)$ and $\mathrm{N}\left({ }^{4} \mathrm{~S}\right)$ atoms can recombine to form $\mathrm{NO}\left(\mathrm{C}^{2} \Pi\right)$. Nightglow emission is generated by the deexcitation of this state. These excited NO molecules relax by emitting photons in the UV $\delta$ and $\gamma$ bands through cascades via the $\mathrm{A}^{2} \Sigma\left(v^{\prime}=0\right)$ state. Nightglow from the NO ultraviolet $\delta$ and $\gamma$ bands are therefore indicators of the atomic $\mathrm{N}$ and $\mathrm{O}$ fluxes from the dayside to the nightside and down into the mesosphere. Due to the higher abundance of $\mathrm{O}$ compared to $\mathrm{N}$ in the nightside mesosphere, the limiting factor for this emission is the atomic nitrogen flux descending toward the atmospheric layer where $\mathrm{N}$ atoms recombine with $\mathrm{O}$ to produce $\mathrm{NO}$ in the excited $\left(\mathrm{C}^{2} \Pi\right)$ state. In the simplest approximation, the emission rate equals the downward flux of atomic nitrogen: one atom, one photon, as originally pointed out by Stewart et al. (1980) and confirmed by the model of Bougher et al. (1990). A summary of key reactions, branching ratios and rates is presented in Stiepen et al. (2017), hereafter Stiepen17.

NO recombination nightglow was discovered at Mars by Bertaux et al. (2005), with limb observations showing an emission peak reaching $2.2 \mathrm{kR}$ at an altitude of $\sim 70 \mathrm{~km}$. The emission required an estimated downward flux of $2.5 \times 10^{8} \mathrm{~N}_{\text {atoms }} \mathrm{cm}^{-2} \mathrm{~s}^{-1}$, about one third of the estimated production of $\mathrm{N}$ atoms by EUV photodissociation of $\mathrm{N}_{2}$ molecules on the dayside. Based on the analysis of 21 SPICAM limb scans, Cox et al. (2008) performed a first study of the correlation between the emission peak brightness and altitude versus geographical factors (latitude and local time), and external factors (the interplanetary magnetic field and solar activity). They reported a large variability in NO nightglow and a lack of apparent correlation between these factors, probably a consequence of the small size of the dataset. SPICAM also serendipitously observed the NO nightglow emission while making stellar occultation observations. Gagné et al. (2013) identified 128 SPICAM stellar occultation NO emission detections out of 2215 observations. They compared their seasonal and latitudinal distribution to calculations from the Mars general circulation model developed at the Laboratoire de Météorologie Dynamique (LMD-MGCM) and described by Forget et al. (1999) and GonzálezGalindo et al. (2009). Gagné et al. showed that the model predicted brighter NO nightglow during winter at polar latitudes, while during equinoxes it predicted maximum emission at both poles with an equatorial enhancement during equinoxes. The observations were too limited to offer strong support to the conclusion, though. Stiepen et al. (2015) compiled 10 years of SPICAM stellar occultation and limb observations of NO nightglow to study the variability of the summer-to-winter hemispherical circulation in the upper atmosphere of Mars. Their data set extended the observations used by Cox et al. (2008) and Gagné et al. (2013). They found that the NO nightglow layer is centered at $72 \pm 10.4 \mathrm{~km}$ and that the number of NO nightglow detections 
112 increased during periods of higher solar activity, in agreement with the paradigm of the dayside 113 production of $\mathrm{N}$ and $\mathrm{O}$ atoms. They produced maps of the brightness and altitude of the 114 emission, though with large gaps in coverage due to observational limitations.

The first MAVEN/IUVS study of the nitric oxide nightglow was based on limb scans (Stiepen17). They analyzed IUVS observations of NO nightglow over the northern hemisphere during three seasons: winter in the north, fall equinox in the south, and northern summer at equatorial latitudes. They characterized the brightness (from 0.2 to $30 \mathrm{kR}$ ) and altitude (from 40 to $115 \mathrm{~km}$ ) of the nightglow layer, as well as its average topside scale height $(11 \mathrm{~km})$. They discovered the signature of atmospheric waves forcing longitudinal variability, associated with an increased airglow brightness peaking near longitudes $10^{\circ}$ and $170^{\circ}$ in the northern hemisphere winter $\left(240^{\circ}<\mathrm{L}_{\mathrm{s}}<295^{\circ}\right)$, and longitudes $-75^{\circ}, 20^{\circ}$, and $140^{\circ}$ during northern summer $\left(75^{\circ}<\mathrm{L}_{\mathrm{s}}<\right.$ $\left.115^{\circ}\right)$. In contrast, the limb data suggested an absence of longitudinal intensity variation during fall equinox in the southern hemisphere. They also showed that the LMD-MGCM globally reproduces some of the trends of the NO nightglow emission and its seasonal variation, but also indicated large discrepancies in brightness, by as much as a factor of 50 fainter in the model during northern winter at low- to mid- latitudes.

Nightglow emissions from other species have also been observed on the Martian nightside. $\mathrm{O}_{2}$ and $\mathrm{OH}$ emissions are concentrated in the polar night region and result from transport of $\mathrm{O}$ and $\mathrm{H}$ atoms produced on the dayside by photodissociation. Both are carried into the dark winter polar regions where they flow down and recombine to produce $\mathrm{O}_{2}\left({ }^{1} \Delta\right)$ and vibrationally excited $\mathrm{OH}$. The $\mathrm{O}_{2}$ nightglow at $1.27 \mu \mathrm{m}$ corresponding to the infrared atmospheric a ${ }^{1} \Delta \rightarrow X^{3} \Sigma(0,0)$ forbidden transition was observed from Mars Express with the OMEGA (Bertaux et al., 2012) and SPICAM IR (Federova et al., 2012) instruments, from the Mars Reconnaissance Orbiter (MRO) CRISM instrument by Clancy et al. (2012, 2013a) and Rosetta by Migliorini (2013). This emission bears some resemblance to the NO nightglow as it arises from three-body recombination of $\mathrm{O}$ atoms $\left(\mathrm{O}+\mathrm{O}+\mathrm{CO}_{2} \rightarrow \mathrm{O}_{2}\left({ }^{1} \Delta\right)+\mathrm{CO}_{2}\right)$ carried from the dayside to the nightside. The results from all instruments indicate that the emission layer is located between 40 and $60 \mathrm{~km}$ in both winter and equinoctial polar regions. Simulations with the LMD model (Gagné et al., 2012; Clancy et al., 2012, 2013a) showed good agreement with LMD simulations of the vertical and latitudinal distribution, especially when including interactive aerosol forcing. Clancy et al. (2013b) also measured the characteristics of the $\mathrm{OH} \Delta \mathrm{v}=0$ and 1 Meinel bands with the CRISM instrument between $70^{\circ}$ and $90^{\circ}$ near the winter pole. They found the location and vertical profile to be very similar to the $\mathrm{O}_{2}\left({ }^{1} \Delta\right)$ emission. They reached good agreement with LMD simulations, confirming the ability of the model to adequately reproduce the mean features of the odd oxygen and hydrogen photochemistry and their transport by global circulation in this altitude range. In addition to nightglow remote sensing, MAVEN/NGIMS in situ helium bulge measurements paint a similar picture of the important of nightside polar downwelling (Elrod et al., 2017).

Comparable processes create nitric oxide nightglow on Earth (e.g., Tennyson et al., 1986; Eastes et al. 1992) and Venus (e.g., Stewart et al., 1980), where it has been observed and extensively studied. The Venus case, with its $\mathrm{CO}_{2}$-dominated atmosphere, offers the most insightful comparison nto Mars. Both $\mathrm{CO}_{2}$ and $\mathrm{N}_{2}$ are dissociated on the Venus dayside and carried to the nightside by subsolar to antisolar global circulation, where they recombine and produce the NO $\delta$ and $\gamma$ bands. Bright spots have been observed with Pioneer Venus (Bougher et al., 2006) and Venus Express instruments (Stiepen et al., 2013; Royer et al., 2010) at varying 
157 locations in the vicinity of the antisolar point (midnight on the equator) with brightness changing 158 from day to day. When combined into long-term statistical maps (Stewart et al., 1980; Bougher 159 et al., 1990; Royer et al., 2016; Stiepen et al., 2013; Gérard et al., 2017)) a bright, nearly-circular 160 region appears spanning about 5 hours in local time and has a full-width at half-maximum of 161 about $50^{\circ}$ in latitude. It is located near the equator and shifted toward dawn by about 2 to 3 162 hours of local time. The driving circulation pattern at these altitudes is a single Hadley cell 163 circulating from the dayside to nightside, apparently with an offset caused by the Venus 164 atmosphere's super-rotation. In the absence of seasons, the circulation appears relatively stable. 165 GCM simulations by Bougher et al. (2006) and Brecht et al. (2011) have confirmed the validity 166 of the general concept. They were able to reproduce the main characteristics of the observed 167 nightglow. Gravity waves and planetary waves (i.e., Kelvin and Rossby waves) have been 168 suggested as the sources of the observed fluctuations of brightness and morphology for both the 169 Venus NO and O2 nightglow emissions. GCM modeling efforts combining these sources have 170 recently been able to reproduce a significant portion of the amplitude of these fluctuations 171 (Brecht et al., 2019).

172 In the study that follows, we use IUVS's disk imaging capabilities during the apoapse 173 phase of the MAVEN orbit to obtain ultraviolet images of the Mars NO nightglow emission. 174 These represent the first observations of Mars nightglow in nadir view. The dataset offers far 175 more complete coverage of latitude, longitude, season and local time than was previously 176 possible, allowing expanded insights into global circulation and the factors that control it. This 177 initial study focusses on long-term seasonal averages, and therefore cannot address shorter-term 178 phenomena. Those will be addressed in a subsequent publication. 


\section{Instrument, observations, and data analysis}

\subsection{MAVEN's Imaging UltraViolet Spectrograph}

The Imaging UltraViolet Spectrograph is MAVEN's sole instrument for remote sensing of Mars and its atmosphere (McClintock et al., 2015]). This study uses the mid-ultraviolet (MUV) channel spanning 180 to $340 \mathrm{~nm}$ at $\sim 1.2 \mathrm{~nm}$ spectral resolution. IUVS uses a long, narrow slit $\left(10^{\circ} \times 0.06^{\circ}\right)$ placed in the focal plane of the telescope as an entrance to the spectrograph, which defines the instrument field of view. The instrument uses image intensifiers for UV sensitivity, using high voltages when viewing the nightside and using low voltages when viewing the dayside. The instrument is mounted on the Articulated Payload Platform (APP) which can orient its field of view relative to Mars. During the apoapse portion of the MAVEN orbit ( $\sim 6000 \mathrm{~km}$ above the surface), IUVS uses its scan mirror to obtain multiple swaths across the planet as the spacecraft moves. The swaths can be combined to produce an image of the planet with pixel resolution of about $20 \mathrm{~km}$ at the sub-spacecraft point at apoapsis (Figure 1a). Spectral range and binning are optimized for the science objectives of the observation and adapted to the available data rate. This study uses IUVS nightside apoapse disk observations taken between 30 March 2016 and 31 July 2018, corresponding to MAVEN orbits 2915 through 7468. To accommodate high spatial resolution data when the available data rate was low, data products from orbits 3925 to 6932 (4 October 2016 to 24 April 2018) used 40 spectral bins (195 to $221 \mathrm{~nm}$ ) instead of 174 spectral bins (185 to $299 \mathrm{~nm}$ ) while keeping the spectral resolution unchanged. The wavelength range for the 40 spectral bins records the three strong delta bands $\left(\Delta v^{\prime \prime}=1,2,3\right)$ in Figure $\left.1 b\right)$. IUVS level 1B data used are available in the Planetary Data System, labeled v13_r02 tagged with "apoapse".

\subsection{Spectral analysis}

Nightside spectra consist primarily of emissions from nitric oxide, though solar continuum can contaminate the spectrum near the terminator, and auroral emissions can occur anywhere during an auroral event (e.g., Schneider et al., 2015). We minimize the error introduced from dark current and its subtraction by using the average dark image per orbit created by coadding multiple dark images taken during a single orbit.

To isolate the NO emission brightness, we use a multilinear regression technique (MLR) to fit the observed spectrum (Stevens et al., 2015). The method is functionally equivalent to that used by Stiepen17, including the use of identical templates and spectral ranges. We used templates derived from IUVS observations isolating the individual spectral components with negligible levels of the other components. The fit yields spectral component contributions for NO nightglow, solar continuum, and a constant term indicating the presence of high background or other artifacts. The observed contributions from the CO Cameron bands (175-270nm) and the Ultraviolet Doublet $(289 \mathrm{~nm})$ were negligible in the dataset, due to the lack of aurora in this time frame, and were not included from the fit. (A short period of known auroral activity (Schneider et al., 2018) was excluded from the dataset.) Examination of high SNR data over the course of the dataset demonstrated that no wavelength zero-point corrections were necessary.

We quantified the NO nightglow ultraviolet emission in instrumental units by summing the nightglow fit over the wavelength range of the NO $\delta$ and $\gamma$ bands (Figure 1b). The three NO $\delta$ band features captured with 40 spectral bins (Figure 1b) account for less than half of the total NO radiance observed by the MUV channel and must be corrected. The validity of combining 
datasets at the two binnings was tested by comparing fits to a 40-bin subset of 174-bin data vs. fits from the full 174-bin data, and finding negligible differences.
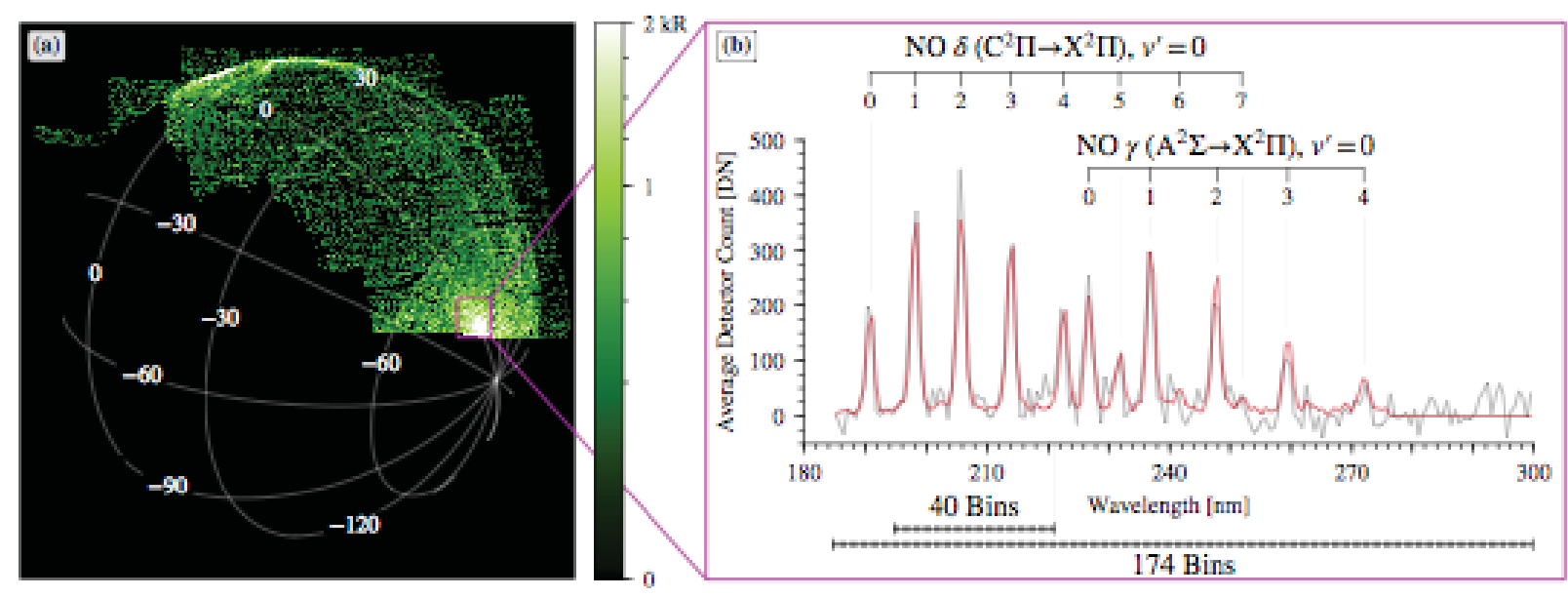

Figure 1a. Spherical projection of level 1C NO nightglow brightnesses observed during orbit 3241 on 30 May 2016 at $\mathrm{Ls}=161^{\circ}$ during Mars Year 33. The colormap shows the total NO nightglow brightness obtained by fitting the $\mathrm{NO} \delta$ and $\gamma$ band spectral template. The image shows the expected enhancement near the southern winter pole, but also patchy equatorial enhancements of comparable magnitude.

231 Figure 1b. MUV spectral fit of NO nightglow. The black line shows the spectrum observed within the box near the terminator in Figure 1a containing about 100 spatial pixels. Other fitted spectral components have been subtracted; the template is shown in red. The fitted brightness is $1.68 \pm 0.04 \mathrm{kR}$. The two spectral regimes used for binning and fitting for different observations are shown along the bottom.

In the final step of spectral analysis, we converted brightnesses in instrumental units to kiloRayleighs $(\mathrm{kR})$ using a calibration curve. We correct for the different binnings described above by scaling 40 -spectral-bin data up by factor of 2.2 in order to combine them 174-spectralbin data. IUVS was calibrated using UV-bright stellar observations, scaled by instrument geometric factors appropriate for extended source observations. Intensities presented in this study are linearly dependent on the absolute calibration. The intensity values are affected by a $30 \%$ systematic wavelength-independent uncertainty due to the calibration. The MUV detectors have recently been recalibrated using bright stars in the airglow slit (the central portion) resulting in a wavelength-dependent 10 to $20 \%$ reduction in intensities for most of the MUV emissions compared to previous stellar observations made in the occultation keyhole at one end of the slit. This recalibration also affects the prior MAVEN/IUVS NO nightglow results (Stiepen17) in which the reported nightglow intensities must be reduced by about $17 \%$. The updated calibration curve will be applied to all IUVS data products on the Planetary Data System (including the 17\% correction to those in this work) at a future date.

\subsection{Data coverage and quality}

IUVS nightside apoapse disk observations span from March 2016 to 31 July 2018 (orbits 2915-7468). The selected observations started at $\mathrm{L}_{\mathrm{s}}=130^{\circ}$ during Mars Year 33 (MY 33) and continued through to $\mathrm{L}_{\mathrm{s}}=221.5^{\circ}$ during MY 34. Data gaps exist when MAVEN's evolving orbit 
did not place apoapse at a suitable location for nightside observations. We eliminated data with solar zenith angles $(\mathrm{SZA})<110^{\circ}$ to restrict solar or dayglow contamination of nightglow spectra. We further eliminated individual spectra which produced MLR fitted values for solar continuum or a constant term exceeding thresholds we determined as contributing significant contamination to the nitric oxide signal. For data with 40 spectral bins (about $75 \%$ of the data), we eliminated pixels with a solar continuum component greater than $1.15 \mathrm{kR}$ or a constant term greater than 2 $\mathrm{kR}$. For data with 174 spectral bins (about $25 \%$ of the data), we eliminated pixels with a solar continuum greater than $5 \mathrm{kR}$ or a constant term greater than $9.2 \mathrm{kR}$. Data do not cover all latitudes at all solar longitudes due to orbital limitations. The SZA cutoff prevents observations during daytime and at the summer poles. These cutoffs prevent contaminated data from entering the analysis, as verified by visual examination of the data while selecting the threshold values. No systematic effects on fitted brightness were detected even near the planet's terminator due to the conservative cutoffs used.

The filtered dataset based on 2941 apoapse images contains more than 41 million independent measurements of vertically integrated NO brightness, each tagged with latitude, longitude, local time and solar longitude. We only used pixel locations on the Mars disk (lines of sight intercepting the disk instead of passing above the limb) with a correction for emission angle. For emission angles less than $50^{\circ}$ we multiply by the cosine of the emission angle, to diminish the brightness to what would be observed at exact nadir viewing. For emission angles between $50^{\circ}$ and $85^{\circ}$ we use a numerical Chapman correction (Smith and Smith, 1972) with a Mars radius of $3390 \mathrm{~km}$, NO nightglow layer altitude of $80 \mathrm{~km}$, and atmospheric scale height of $11 \mathrm{~km}$. Pixels lying above Mars' physical limb cannot be corrected in the same manner, and we will use them in a later study.

Data quality has been ensured by visual inspection of sample data under the full range of observed radiances and observing conditions. This applies at the faintest levels reported in this work (25 R), where the unique spectral structure of NO is readily discernable in spatial or temporal averages of 5000 samples or more. This number of samples corresponds to areal averages over a square area $\sim 300$ by $300 \mathrm{~km}$ in a single integration of 3.4 seconds, or corresponding temporal integral over our $20 \mathrm{~km}$ diameter spatial resolution element in about 15 minutes. At the brightest levels (about a hundred times brighter) the spectral shape is distinct in correspondingly smaller areas and timespans. All plots and figures employ summations over much greater areas and timespans, such that all the observation geophysical variations are far larger than statistical noise. The figures in following sections confirm this conclusion in the relatively smooth variation over the independently calculated pixels in maps and line plots.

Figure 1a conveys a sense of the excellent data quality in an individual image, but cannot convey the substantial variability frame-to-frame or day-to-day. Given this variability, it is all the more remarkable that strong patterns emerge from seasonal averages, as discussed in Section 3.

\subsection{Model description}

In this study we compare observational results to vertically-integrated NO nightglow brightness simulations from the Mars Global Climate Model developed at the Laboratoire de Météorologie Dynamique (LMD-MGCM) (Forget et al., 1999; Gonzalez-Galindo et al., 2009). We use the same version used by Stiepen17, which was also used to build the Mars Climate Database version 5.3 (Millour et al., 2018). The main difference between our simulations and those in Stiepen17 is that we have used the solar activity and dust load observed during the 
period of IUVS observations described here as inputs, while Stiepen17 used a generic scenario for average solar conditions and a climatological dust scenario appropriate for years without a global dust storm. In particular, the solar variability during MY 33 and 34 have been included as described in González-Galindo et al. (2015). For the dust scenario, we included the observed dust load variability during MY 33 using the procedure described in Montabone et al. (2015). For MY 34 we used the climatological dust scenario, appropriate for the period analyzed here before the onset of the global dust storm beginning in May 2018 at a solar longitude of approximately $180^{\circ}$. The model does not include effects of non-orographic gravity waves.

The LMD-MGCM was adapted to include key physical processes relevant to the nightglow emission process: photochemical creation of atomic nitrogen and oxygen on the dayside, horizontal and vertical transport to the nightside, and recombination reaction rates based on densities and temperature. The influence of changing EUV flux controlling dissociation and ionization is included in the model. The model currently includes only production by photodissociation, and omits $\mathrm{N}_{2}$ electron-impact dissociation, identified by Bougher et al. (1990) as an important source of odd nitrogen. The model brightness is linearly dependent on the production of atomic $\mathrm{N}$ on Mars' dayside, so this limitation will affect quantitative agreement.

As a check, we calculated two forms of model output to examine potential observational bias: output spanning all latitudes, longitudes, nightside local times and solar longitudes, and point-by-point model calculations matched to the exact geometry of individual data points. There were no discernible differences between the two where observations exist, giving confidence that conclusions reached with this dataset are not artifacts of the observational coverage. With the exception of Figures $2 \mathrm{~b}$ and 4 , all model outputs are point-for-point matches to observational data.

\section{Results}

\subsection{Latitudinal and seasonal control of NO nightglow emission}

Latitude and season are the strongest influences on global circulation patterns, and Figure 2 a confirms they exert strong control on the brightness of nightglow. The winter poles show very strong enhancements with steep latitudinal gradients towards the equator spanning nearly two orders of magnitude. While Stiepen 17 measured a strong latitudinal gradient up to $60^{\circ}$ north and south latitude, the imaging observations presented here are the first to span the full polar regions. Observational limits do not allow estimates of the timing of the seasonal onset or decline of the polar enhancements. We note an asymmetry between the northern winter pole and the southern winter pole brightness, with the north brighter by a factor of 2 to 3 . Part of this asymmetry is probably attributable to the higher solar flux at perihelion. During northern winter, MAVEN's EUV Monitor (Eparvier et al. 2015) measured total irradiance between 1-45 nm a factor 1.43 larger than that during the southern winter, attributable almost entirely to the reduced distance, with no significant difference in solar activity. The observed increase in insolation and corresponding dissociation rate is not enough to explain the entire effect. Models show that increased insolation and a dustier atmosphere drive more rapid meridional circulation during southern summer (Bougher et al., 2006; Bell et al., 2007, González-Galindo et al., 2009), which would transport dissociation products more rapidly to the northern summer pole. These two effects combined are plausibly sufficient to explain the brightness asymmetry, but a more quantitative analysis is beyond the scope of this work. 
Imaging measurements identify equatorial enhancements during equinox seasons. This differs slightly from the equatorial enhancements first noted by Stiepen 17 during southern winter. In both cases, the emission primarily takes the form of patchy enhancements as seen in Figure 1a, as opposed to a uniform equatorial belt. We discuss the nature and distribution of these patches in the subsequent sections.

Figure $2 \mathrm{~b}$ shows LMD-MGCM nightglow predictions for the solar and dust conditions appropriate to the season and Mars year. Note the color bar extends downward one additional order of magnitude, indicating the model predicts extremely faint emissions away from the seasonal enhancements. The overall structure is similar between observations and model, especially the winter pole brightenings and the northern winter enhancement. Equatorial equinoctial brightenings are present in both observations and model, though the observed equatorial peak is a factor of several brighter than the modeled peak. The model enhancements are generally more extended in solar longitude and latitude, but observational limits prevent a deeper comparison.

Figure $2 \mathrm{c}$ quantifies the brightness differences between Figures $2 \mathrm{a}$ and $2 \mathrm{~b}$. We find that the model underestimates emissions by factors between 2 and 10 at northern- and mid-latitudes, while brightnesses in the south are comparable. This differs from the conclusions of Steipen17, who found the model was brighter near the north pole, while fainter elsewhere, though this may have been biased by less complete observational coverage in latitude and solar longitude. The area-weighted integrals of the curves in Figure 2c show that the observations' average brightness is 1.9 times brighter than the models. The likely cause of this discrepancy is the net production of atomic nitrogen on the dayside, rather than any profound error or incompleteness in the physics of transport or subsequent chemistry. The deficit could be met through inclusion of additional dayside sources such as electron impact dissociation, changes in reaction rate coefficients, 

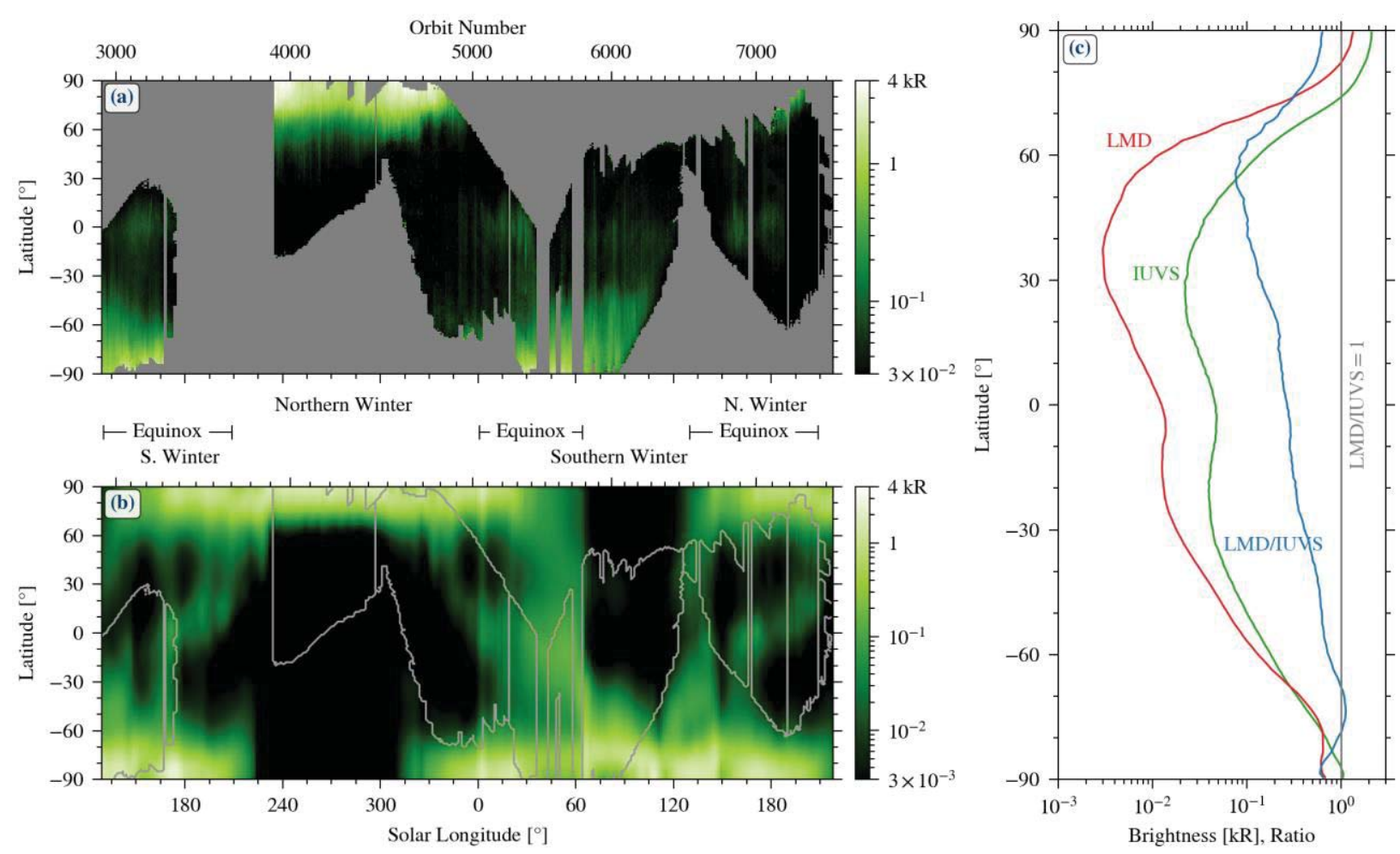

Figure 2a. Climatology map of NO nightglow brightness from the full disk dataset binned by $1^{\circ}$ in latitude and solar longitude. The data are averaged over all observed longitudes and local times. Note polar brightening during northern winter $\left(\mathrm{L}_{S} \sim 270^{\circ}\right)$, southern winter $\left(\mathrm{L}_{\mathrm{S}} \sim 90^{\circ}\right)$ and the equinoxes $\left(\mathrm{L}_{\mathrm{S}} \sim 160^{\circ}, 40^{\circ}\right.$, and again $\sim 160^{\circ}$ ). The edges of the dataset are determined by observational coverage and solar stray light limits. Seasonal demarcations are based on similarities in observed behavior rather than formal solar longitude limits.

Figure 2b. LMD-MGCM calculations of the zonal mean NO brightness at all latitudes and solar longitudes during the observation period. The grey outline indicates the data boundaries from figure $2 \mathrm{a}$, showing that the observations sampled the majority of key phenomena including both polar nights and the transition periods during the equinoxes. Note that the color bar extends one order of magnitude lower and for the panel above.

Figure 2c. Zonally averaged NO nightglow brightness across all solar longitudes plotted vs. latitude in $1^{\circ}$ bins. The grey line marks $1 \mathrm{kR}$ for the red and green curves, and indicates a ratio of unity for the blue curve. Statistical uncertainties in these mission-long averages are negligible on the scale of these plots, while the observed variability among observations at the same latitude is substantial. The faintest level of emission $\left(25 \mathrm{R}\right.$ observed at about $\left.30^{\circ} \mathrm{N}\right)$ is a confirmed detection as opposed to an upper limit, so the difference from the LMD curve is significant.

Next, we examine local time behavior of the emission, with an emphasis on understanding the effect that the transition from day to night makes on the emission. Figure $3 \mathrm{a}$ shows all observations as functions of local time and latitude, averaging over all observed geographic and solar longitudes. The data show that polar emissions are bright and relatively 
constant in local time due to the persistent darkness. At equatorial latitudes, the data show a peak in emission in the evening hours and a strong decline towards the morning terminator. Combining the results shown in Figure $2 \mathrm{a}$ and $3 \mathrm{a}$, the equinox enhancements at the equator peak in the evening hours.

Figure $3 \mathrm{~b}$ shows point-for-point simulations from the LMD-MGCM model in the same format. The polar regions exhibit minimal local time variation, as expected since winter pole latitudes do not experience daytime. At the equator, the model predicts a continuous brightness increase through the evening, peaking in the late morning hours just before sunrise. This effect enhanced at mid-southern altitudes. While it is reassuring that both observation and model indicate an equatorial nightside enhancement, the disagreement between the observed equatorial pre-midnight peak and the modeled pre-dawn peak indicates a substantial gap in our understanding of what drives equatorial circulation at equinox seasons.

The LMD-MGCM provides diagnostic information on the conditions that drive the emissions. The most probable cause for the nightside equatorial spot of Figure $3 \mathrm{a}$ or $3 \mathrm{~b}$ is vertical winds carrying the atomic species downward to higher densities where they recombine. Figure 4 shows the LMD-MGCM prediction of vertical winds during equinox seasons. The model reproduces the basic expectation of equatorial upwelling on the dayside during equinox seasons and downwelling on the night side, though maximum downwelling occurs at a later local time than observed. The local time and altitude variability of the emission and the vertical winds in the model (Figures $4 \mathrm{c}$ and $4 \mathrm{~d}$ ) below about $100 \mathrm{~km}$ are similar to that expected from the vertical propagation of the migrating diurnal tide. This suggests that the different local time peak of the emission in the model compared to the observations is produced by an incorrect representation of the diurnal tide in the model. A possible cause is the lack of non-orographic gravity waves effects in the model. Previous studies (e.g., Medvedev et al., 2011) have shown the importance of the inclusion of the effects of such waves in 3D models for matching the thermal and dynamical structure of the mesosphere. In particular, Gilli et al. (2020) have shown that their inclusion in the LMD-MGCM significantly improves comparisons with observations of the amplitude of the diurnal migrating tide from Mars Climate Sounder (MCS) on the Mars Reconnaissance Orbiter (MRO).

A similar analysis of the polar brightenings also indicates that atmospheric circulation is the driver, but the correspondence with downwelling is less clear. Figure 4a shows that the equinox model predicts bright emission at both poles, even though nightside local times are experiencing upwelling. Detailed analysis of model output offers some clues. First, the zonallyaveraged vertical velocity does indicate downwelling on average, as must be the case with transport from the thermosphere to mesosphere. Furthermore, the model indicates a buildup of atomic $\mathrm{N}$ on the nightside in a region of very long lifetime against loss processes. In the absence of nightside production mechanisms or downwelling, the buildup must be caused by horizontal transport. The same condition is true during the solstices, where the polar regions are further complicated by the dynamics of the polar vortex. The model again finds a substantial buildup of nightside $\mathrm{N}$ consistent with the observed polar brightenings. A deeper investigation of the model to study these polar processes is beyond the scope of this synoptic effort, but is likely to bear fruit as a separate project. 

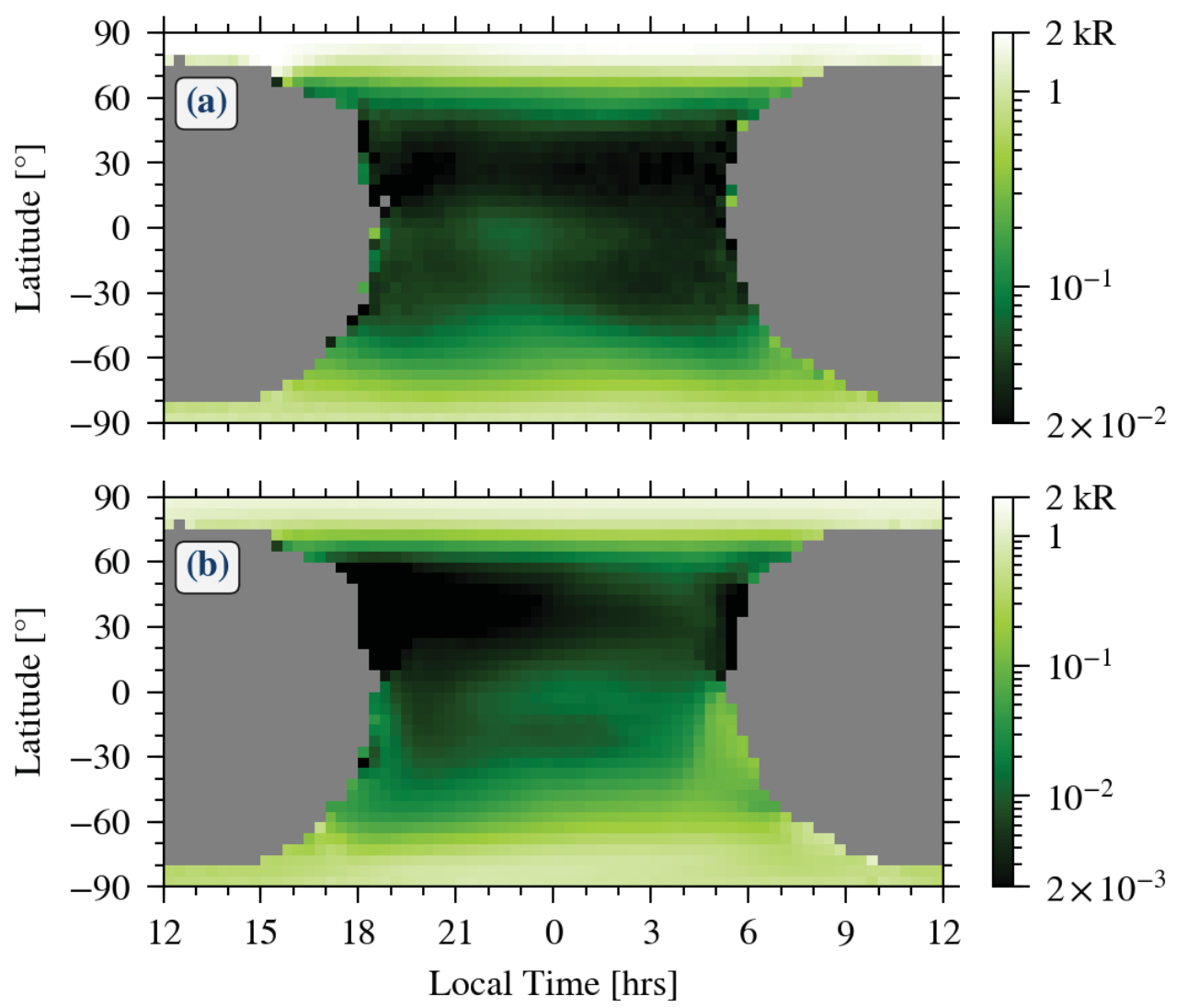

Local Time [hrs]

434 Figure 3a. Observed NO nightglow emission by latitude and local time averaged over our dataset. Different latitude ranges are filled in over different seasons: High-latitude emissions are observed at all local times during each polar night, filling both poles. We observed the equatorial enhancement primarily during equinox seasons. Local time bins are 20 minutes and latitude bins are $5^{\circ}$.

Figure 3b. Average LMD-MGCM calculations for the same conditions as Figure 3a. Note the extra order of magnitude in color scale necessary to display equatorial brightness in the model compared to observations above.

\subsection{Wave structures and atmospheric tides}

Atmospheric tides are widespread phenomena throughout the solar system. Diurnal solar heating of planetary atmospheres, modulated by topography, surface thermal inertia, albedo, and dust loading in the atmosphere can produce tides and global-scale thermal oscillations with periods that are subharmonics of the planetary rotation period (Forbes et al., 2002). These tides can be generally classified as migrating (those components that track the Sun's motion) and nonmigrating. Tides can produce significant deviations from equilibrium values in atmospheric state variables, such as density, pressure, and temperature, and in doing so can affect atmospheric circulation and the horizonal and vertical transport of energy. Tides have important effects on the momentum balance in Mars' atmosphere (Wilson and Hamilton, 1996, Moudden and Forbes, 2008). These far-reaching effects imply that an understanding of the atmosphere is incomplete without an understanding of atmospheric tides. 

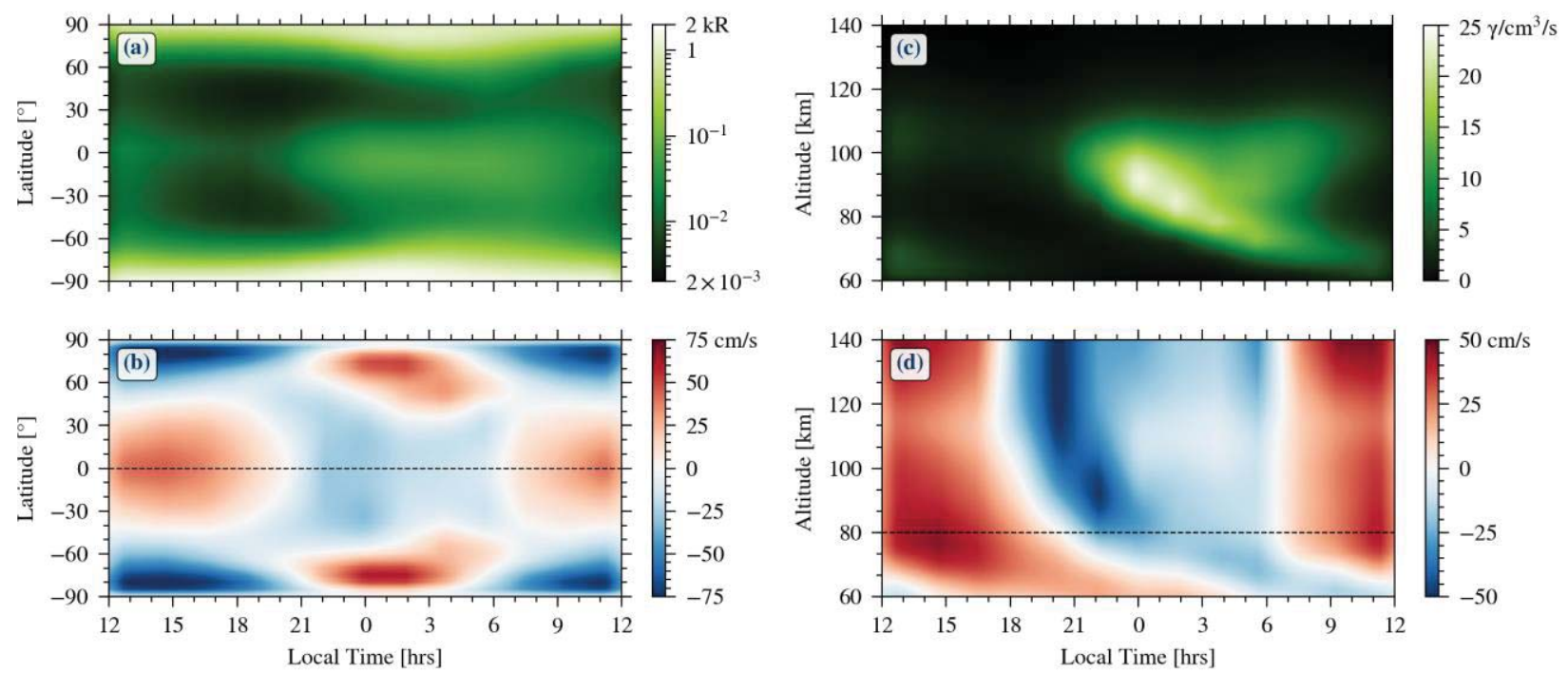

Figure 4a. LMD-MGCM predictions of vertically-integrated nightglow for the equinox season $\left(\mathrm{L}_{\mathrm{s}}=0-30\right)$. It shows a nightside equatorial enhancement, though less spatially confined and later in local time than observed. Note that these plots show a global seasonal average (i.e., not restricted to observed times \& locations), so it is not an exact match to Figure $3 \mathrm{~b}$.

Figure 4b. Vertical winds at $80 \mathrm{~km}$, confirming the intuitive pattern of dayside upwelling (red) and nightside downwelling (blue) where emission is maximized. The dashed line indicates where this panel intersects Figure 4d.

Figure 4c. LMD-MGCM predictions of nightglow volume emission rate in a vertical slice at the equator for the equinox season $\left(\mathrm{L}_{\mathrm{s}}=0-30\right)$.

464 Figure 4d. Vertical wind velocity as a function of local time and altitude. Note that the maximum downwelling shifts from pre- to post-midnight looking lower in the atmosphere, indicating the importance of zonal winds in deflecting vertical flow. Note the correlation between downwelling (blue) and volume emission rate (green) in Figure 4c. The dashed line indicates where this panel intersects Figure $4 \mathrm{~b}$.

Previous studies have found that atmospheric tides and associated wave features affect different latitude and altitude ranges during different seasons. Mars' mid-latitudes are affected by planetary waves including standing and traveling waves (e.g., Banfield et al., 2003, 2004; Hinson 2006; Lewis et al., 2016). Other studies have reported longitudinally-dependent wave and tide activity in the upper atmosphere of Mars during northern hemisphere summer, fall and winter seasons (Keating et al., 1998; Wilson et al., 2002; Bougher et al., 2004; Angelats i Coll, 2004; Lo et al., 2015; England et al., 2016; Stiepen17; Gröller et al., 2018; Bougher et al., 2017). Lo et al. (2015) and Medvedev et al. (2016) have discussed nonmigrating tides observed in MAVEN/IUVS airglow observations between altitudes of 130 and $180 \mathrm{~km}$ on the dayside, while England et al. (2016) sample the 165 to $205 \mathrm{~km}$ dayside altitude region using MAVEN/IUVS airglow measurements and MAVEN Neutral Gas Ion Mass Spectrometer (MAVEN/NGIMS) measurements. At mesospheric altitudes, waves and tides have been previously studied using two different datasets. First, Withers et al. (2011) identified strong wave-2 and wave-3 nonmigrating eastward-propagating tides using densities from SPICAM/UV occultations, identifying them as diurnal Kelvin waves DK1 and DK2. (DK2 is also referred to in the literature as DE2, which we discuss below.) Second, Guzewich et al. (2012) analyzed the MRO/MCS temperature dataset, 
finding that tropical latitudes were dominated by non-migrating tides, while stationary planetary waves with wavenumbers 1 and 2 dominated mid and high latitudes of both hemispheres.

The substantial IUVS dataset offers a new opportunity to study wave structures and atmospheric tides. Many prior studies have been based on observations from orbiting platforms fixed in local time (e.g., Mars Climate Sounder on the Mars Reconnaissance Orbiter (Guzewich et al., 2012)), or precessing in local time (e.g., MAVEN/NGIMS and IUVS limb scans, as in England et al. (2019)). These measurements follow a repeating ground track that ties together latitude, longitude, and local time. Other observations have been made from surface assets fixed in latitude and longitude (e.g., the Viking Landers (Hess et al., 1977)). IUVS imaging provides a significant improvement in coverage over past studies by offering simultaneous coverage in both longitude and local time, while also mapping over a range of latitudes. The IUVS dataset offers two significant advantages with respect to previous mesospheric datasets. First, for the first time the polar regions are fully covered (at least during the winter periods). The MCS dataset is restricted to latitudes between $\pm 70^{\circ}$ (Guzewich et al., 2012), while the SPICAM stellar occultations dataset only included four narrow latitudinal and seasonal ranges, none of them extending further than $60^{\circ}$ in latitude (Withers et al., 2011). Second, our dataset offers good local time coverage which avoids aliasing problems, in contrast with MCS measurements which are obtained at only two local times.

We begin with an overview of wave structures identified in the full IUVS imaging dataset spanning more than one Mars year. Figures $5 \mathrm{a}$ and $5 \mathrm{~b}$ show significant longitudinal variability at all latitudes, but more pronounced at the equator, northern polar and southern polar regions. Note in particular the brightening near $\left(0^{\circ}, 0^{\circ}\right)$, and strong features at high northern and southern latitudes. In the following sections we analyze these three regions separately, finding that the wave features are strongly correlated with season and exhibit different behaviors with local time. Nonetheless, the features are so strong and distinct that they still appear in the full dataset average. Many of the observed features are replicated in the LMD-MGCM model simulations (Figure 5c), but analysis will benefit from consideration of the specific seasonal conditions for the occurrence of the wave structure. 

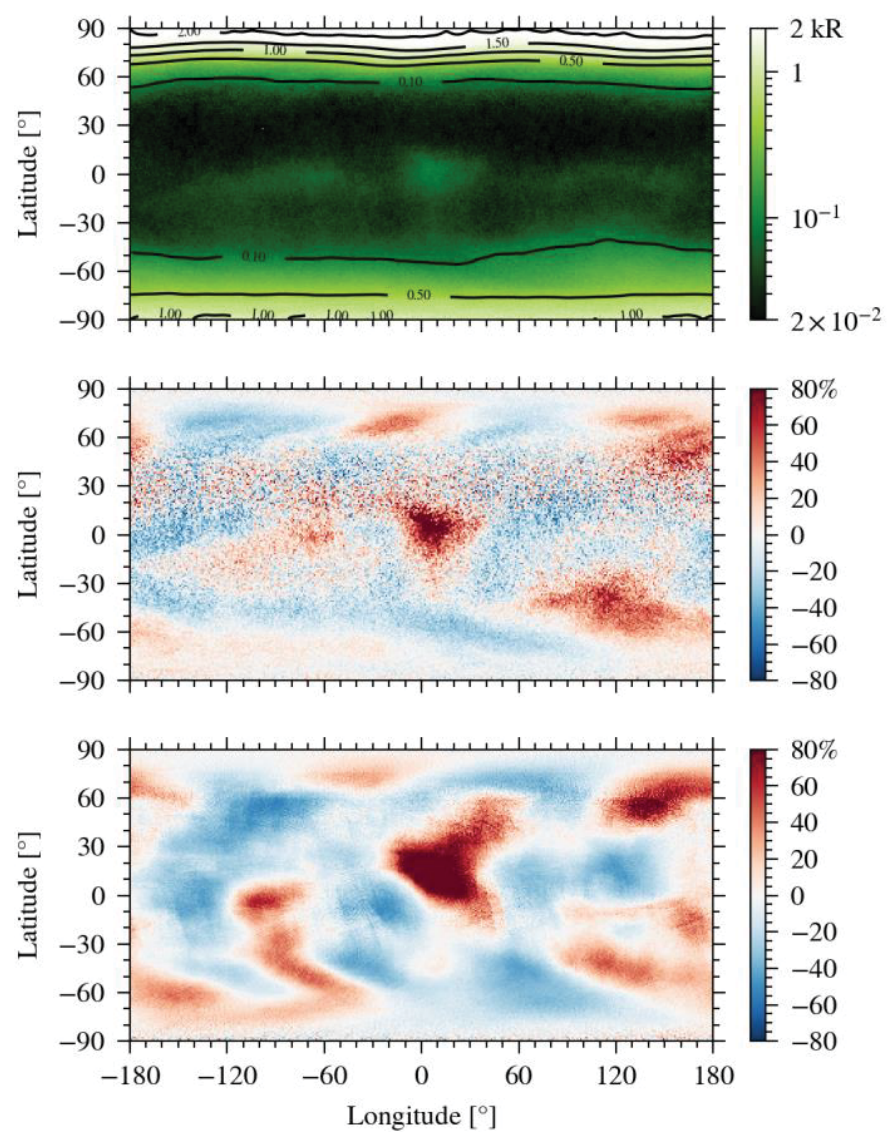

514 Figure 5a. Full dataset average brightness of NO nightglow.

515 Figure 5b. Average brightness of NO nightglow above divided by the mission-long zonal 516 average brightness (Figure 2c) to show the deviations from the mean brightness at all latitudes. 517 The color scale is now shown blue-to-red to indicate variations about the mean.

518 Figure 5c. LMD-MGCM simulations of the same data from Figure 4a divided by the model's zonal average brightness (also from Figure 2c) to show the deviation from the mean brightness at all latitudes.

\subsubsection{Equatorial wave-3 atmospheric tides}

Figure 6 takes a closer look at the equatorial wave structure evident in the mission-long average in Figure 5a. Here we average only the equinox data when the structure was observed: $130^{\circ}<\mathrm{L}_{\mathrm{s}}<175^{\circ}$ during MY 33 (orbits 2917 to 3379, 30 March to 24 June 2016) and $0^{\circ}<\mathrm{L}_{\mathrm{s}}<60^{\circ}$ during MY 34 (orbits 5036 to 5727, 5 May to 12 September 2017). Figure 6a shows a simulated nightside image constructed from all equinox data, with local time varying across the image. Each latitude is divided by its corresponding zonal mean across the entire data set (figure $2 \mathrm{c}$ ), showing a strong enhancement near $\left(0^{\circ}, 0^{\circ}\right)$. Figure $6 \mathrm{~b}$ shows the data from which this was constructed with data from all local times co-added. Two changes from the filtering are evident: first, the intensity of the enhancement near $\left(0^{\circ}, 0^{\circ}\right)$ is amplified; second, side lobes become evident in Figures $6 \mathrm{~b}$ and $6 \mathrm{~d}$, indicating the presence of a wave-3 structure in addition to the bright maximum. Animations of this dataset are provided in the Supporting Information. (It bears 


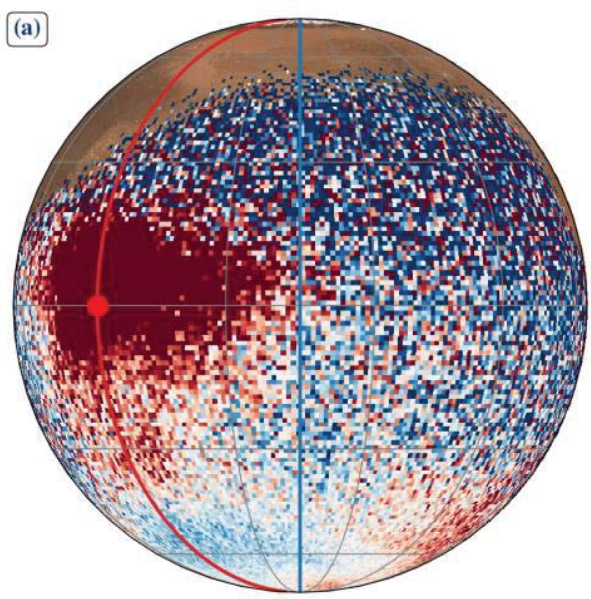

noting that Stiepen17's reported equatorial wave-3 structure mentioned above occurs at a different season not directly comparable to the observations here.)
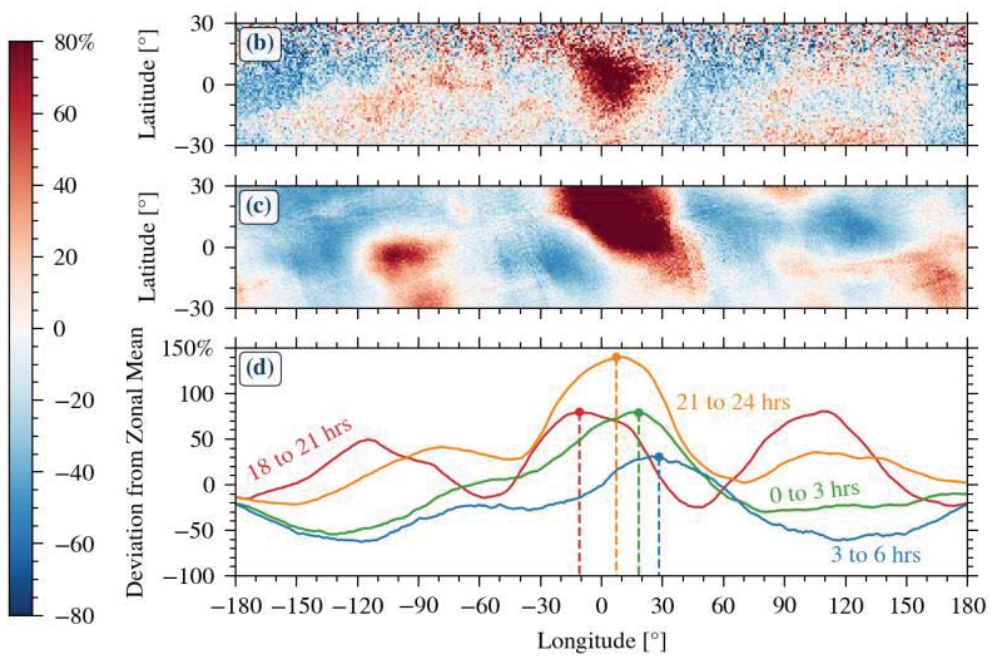

Figure 6a. Nightside image constructed from all equinox data with appropriate geometry from $\mathrm{L}_{\mathrm{s}}=130-175$ in MY33 and 0-60 in MY34. The anti-solar point lies at the disk center; the red line indicates the location of the prime meridian; the blue line indicates midnight, with the evening terminator to the left and morning to the right. The local time at $\left(0^{\circ}, 0^{\circ}\right)$, indicated by the red dot, is 21 hours, when the spot is near its brightest. At each location, we smoothed the data by averaging \pm 1.5 hours around the instantaneous local time.

Figure 6b. Cylindrical projection of the zonal mean variation of NO nightglow brightness for the same equinox period. Note the reddish regions on either side of central red peak constituting secondary maxima around $\pm 120^{\circ}$. The side peaks are more visible in this seasonally-restricted plot than in Figure 5a.

Figure 6c. Cylindrical projection of the zonal mean variation of the LMD-MGCM model NO nightglow brightness matching observational parameters, approximately replicating the threepeaked structure seen in the data (in Figure 6b). Note that the $\left(0^{\circ}, 0^{\circ}\right)$ spot appears even brighter in the model than the data.

Figure 6d. Observed local-time relative variation of the NO nightglow brightness for equatorial latitudes between $30^{\circ} \mathrm{S}$ and $30^{\circ} \mathrm{N}$. The complex structure suggests a combination of wave- 3 and wave- 1 features, and probably some additional modes varying with time. Dashed lines mark the longitudes of the peaks of the curves, showing the eastward progression of the peaks.

The LMD-MGCM model simulations for these conditions are shown in Figure 6c, offering a good match to the observations. An examination of the variables controlling emission in the model confirms a spatially confined region of strong downwelling around $\left(0^{\circ}, 0^{\circ}\right)$ carrying $\mathrm{N}$ and $\mathrm{O}$ atoms down to lower altitudes where they can recombine.

Figure $6 \mathrm{~d}$ shows the changing position of the wave- 3 structure over four local time ranges. Different non-migrating tides can produce an apparent longitudinal wave- 3 structure, 
such as a stationary planetary wave-3 (SPW3), a diurnal eastward-propagating wave-2 (DE2), and semi-diurnal eastward-propagating wave-1 (SE1). These tides can be distinguished by their motion (if any) in local time. The observed average motion of the central peak is about $4.7^{\circ} /$ hour eastward, consistent with the DE2 wave's $5^{\circ}$ /hour rate and inconsistent with other non-migrating tides. In fact, it is the eastward motion of a wavenumber- 2 diurnal tide that turns it into a wave-3 structure when plotted vs. longitude. A tidal decomposition performed on the LMD-MGCM predicted emission (Figure 6c) also indicates that the wave-3 structure is dominated by DE2, with a much smaller contribution by SW1.

The clear identification of DE2 tides in the middle atmosphere at low latitudes is significant in the context of other tide identifications. DE2 has been previously identified as a dominant contributor to observed temperature variability in the lower atmosphere at low latitudes (Wilson, 2000). Wave-3 structures previously observed in the upper atmosphere (such as those derived from MGS aerobraking or ionospheric observations at high northern latitudes near aphelion) have usually been interpreted as the product of the semidiurnal wave-1 SE1 tide (Bougher et al., 2004). However, a significant contribution of the DE2 wave was acknowledged in the tropics (Withers et al., 2003, 2011; Angelats i Coll et al., 2004). Our result indicates that at low latitudes in the mesosphere, DE2 is still the dominant source of variability, in good agreement with the previous analysis of MCS temperature measurements in a similar altitude region (Guzewich et al., 2012). This result helps connect previous lower- and upper-atmosphere observations of this tidal component, providing information about the vertical propagation of the tidal modes (e.g., Moudden and Forbes, 2008; Lee et al. 2009).

The tight confinement of the $\left(0^{\circ}, 0^{\circ}\right)$ spot (and its implication of highly localized downwelling) is one of the most surprising results of this work, including the excellent match with the LMD-MGCM. This suggests that the model captures the driving physics of circulation and tides in the upper mesosphere and lower thermosphere at equinox. The nightside nightglow spot is reminiscent of the statistically averaged NO nightglow brightening observed near the antisolar point on Venus (e.g., Stewart et al., 1979; Bougher et al., 1990; Stiepen et al., 2012; Royer et al., 2016). It suggests that the circulation pattern of Mars' mesosphere during equinox has similarities to Venus's dayside-to-nightside circulation pattern.

\subsubsection{Wave-2 structure at the northern winter pole}

The poles are regions of intense NO emission during the extended winter night, with very strong latitudinal gradients which make wave structures challenging to detect. Figure 7a shows the averaged northern polar brightness for $240^{\circ}<\mathrm{L}_{\mathrm{s}}<360^{\circ}$. Contours show an elliptical distribution around the pole. The long axis of the $1.5 \mathrm{kR}$ contour is about $50 \%$ greater than the short axis, extending southward towards longitudes $-15^{\circ}$ and $150^{\circ}$. Examination of the images contributing to this seasonal mean shows high variability, with a strong tendency for bright patches or fingers of emission near these longitudes at 5-10 $0^{\circ}$ away from the pole. The pole itself is consistently brighter than lower latitudes, but is rarely the brightest location on the planet.

Figure $7 \mathrm{~b}$ shows the average brightnesses divided by the zonal mean, such that the oval structure appears as a longitudinal wave- 2 structure, with a hint of a spiral structure extending westward farther from the pole. The wave amplitude is less than $25 \%$ around the zonal mean, much less than that observed in equatorial regions. 
Figure 7c shows the LMD model simulations corresponding to these observations, presenting a very good wave- 2 match to the observations, with two peaks offset to the west by about $15^{\circ}$ relative to the observations. At this level, the model is evidently capturing the dominant physics.

Figure $7 \mathrm{~d}$ examines the local time behavior of the wave structure, showing a general increase in average brightness as local time progresses. Evidence for tidal motion is ambiguous, as the motion of the peaks is not regular. While the peaks move significantly between the earliest and latest local times, the spiral structure evident in the data links latitudinal structure to longitudinal motion and inhibits further analysis. We therefore cannot distinguish at this level whether the structure is a stationary wave or a non-migrating tide. The potential identification of stationary waves should not be construed as evidence against other wave types such as planetary waves. The seasonal means used here of necessity average out shorter term variations, and it remains possible that such waves are superposed on the stationary waves. In fact, preliminary analysis of model output suggests baroclinic waves are expected, and a subsequent study will search for them in the observations.

The behavior at the nightglow peak altitude can be compared to phenomena at other altitudes, such as ozone in the troposphere. Clancy et al. (2016) observed a prominent wave-2 feature in late northern winter (their Figure 8), but it propagated eastward over a period of days, characteristic of a planetary wave. They also identified a wave-1 stationary wave (their Figure 5) peaking around $-45^{\circ}$ in late northern spring. While this matches one of the NO features at higher altitude, there is no second maximum corresponding to the NO peak at $135^{\circ}$. Further modeling, beyond the scope of this work, will be needed to tie together these phenomena at different altitudes, seasons, and years.

Waves induced by the northern hemisphere topography are well known on Mars at high latitudes and have been shown to propagate well through the eastward jet stream present in the Martian atmosphere at high northern latitudes during spring and summer (Barnes et al., 1996). An analysis of the stationary variations in the temperature fields observed by MGS/TES confirms the presence of a strong wave-2 during northern winter and spring combined with a stationary wave-1 which may explain the observed asymmetry between the hemisphere centered around $30^{\circ} \mathrm{E}$ and the opposite hemisphere centered around $-150^{\circ} \mathrm{E}$ in Figure $7 \mathrm{a}$. MCS observations show that a stationary wave- 2 signature was present at all northern latitudes up to $70^{\circ} \mathrm{N}$ (Guzewich et al., 2012). Our result confirms for the first time the dominance of this wave mode in the mesosphere in the North polar region, at least during the polar winter. 

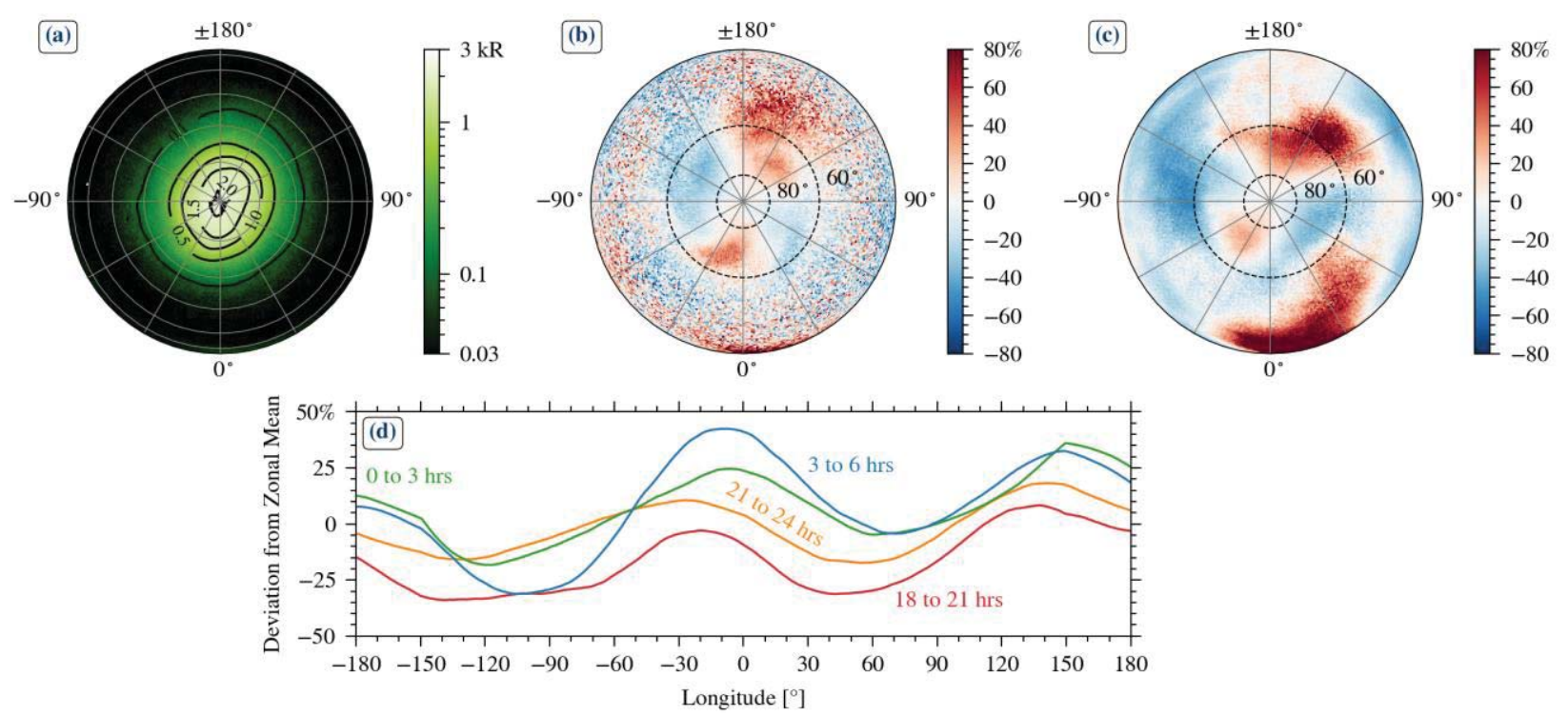

639 Figure 7a. Northern polar projection of the mean brightness of the NO nightglow in the period around northern winter. Polar latitudes were observed exclusively in winter $\left(\mathrm{Ls}=235^{\circ}-350^{\circ}\right.$ during MY33 and $150^{\circ}-210^{\circ}$ during MY 34), while midlatitudes were observed over a broader range of $\mathrm{L}_{\mathrm{S}} \mathrm{solar}$ longitudes. These differences do not affect the wave structure.

Figure 7b. Variation in NO nightglow brightness relative to the zonal mean across all local times. The region selected for the wave analysis in $7 \mathrm{~d}$ is indicated with two dashed parallels at $60^{\circ} \mathrm{N}$ and $80^{\circ} \mathrm{N}$, respectively. The larger variation at latitudes less than $60^{\circ} \mathrm{N}$ is caused by the significantly lower zonal mean brightness (see Figure 2c).

Figure 7c. Same as Figure 7b, but for the LMD model simulations sampled to match the data. The model matches well within the dashed lines. (The red spot at the bottom of the image is the equatorial spot discussed in the previous section.)

650 Figure 7d. Local-time zonal mean variation of the northern polar NO nightglow brightness averaged between $60^{\circ} \mathrm{N}$ and $80^{\circ} \mathrm{N}$ latitude. Each curve shows 3-hour averages.

\subsubsection{Wave-1 structure at the southern winter pole}

During southern polar winter, the average brightness structure also appears as an oval but slightly off-center from the pole (Figure 8a), representing an average of a spatially patchy and temporally variable appearance from orbit-to-orbit. When divided by the zonal mean, we observe a wave-1 feature and a clear spiral pattern in the variation about the zonal mean (Figure 8b), notably different from the north pole wave structure. There is a large positive deviation around $120^{\circ}$ longitude, and a corresponding negative deviation near $30^{\circ}$ longitude.

Figure 8c shows the LMD model simulations for these observations. At most latitudes the model predicts a wave- 2 structure differing from the observed wave- 1 structure. One model maximum lies in the longitude range from $-150^{\circ}$ to $+120^{\circ}$, in good correspondence to the observations, but an additional peak around $-60^{\circ}$ has no observed counterpart. Whatever physics 664 model. 
Figure $8 \mathrm{~d}$ shows the local-time decomposition of the average amplitude of the zonal mean variation between latitudes $73^{\circ} \mathrm{S}$ and $44^{\circ} \mathrm{S}$. The average intensity starts very low in the early evening. It increases with local time past midnight, as it does at the north, but then falls slightly in the last interval. The wave- 1 structure is most prominent after midnight, but there is no discernable motion. This leads us to conclude that the observed peak is likely caused by a stationary planetary wave-1. Analysis of the model results at $70^{\circ} \mathrm{S}$, where model predictions are most similar to observations, show a combination of a wave-1 quasi-stationary wave with the influence of the diurnal tide and a baroclinic wave- 1 with a period of about 7 to 10 sols. As for the northern winter case, the seasonal average masks the signature of the shorter period waves, emphasizing the importance of the stationary wave.

Strong wave-1 stationary waves signatures have been previously observed in the lower atmosphere by the Thermal Emission Spectrometer (TES) on Mars Global Surveyor, (e.g., Barnes et al. (2003)) and in the mesosphere by MCS (Guzewich et al., 2012). Our measurements present complete latitudinal coverage offering new insights into the structure of the stationary waves in both winter polar regions.
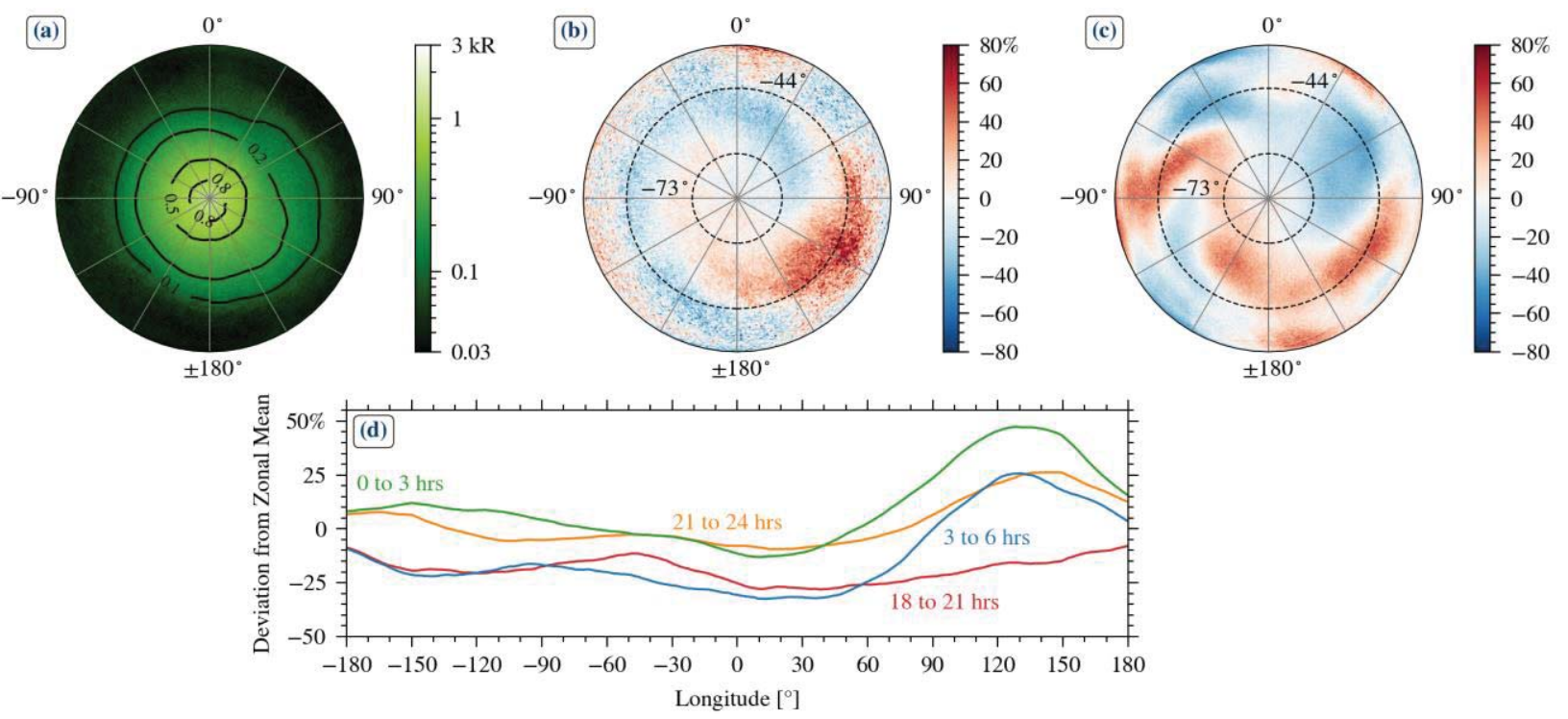

Figure 8a. Southern polar projection of the NO nightglow brightness in the period around southern winter (same as Figure 7 for the north). Data poleward of $60^{\circ} \mathrm{S}$ were obtained between $\mathrm{L}_{\mathrm{s}}=130^{\circ}-175^{\circ}$ in during MY 33 and $24^{\circ}-106^{\circ}$ during MY 34 while midlatitudes were observed over a broader range of solar longitudes.

Figure 8b. Southern polar projection of the zonal mean variation of the NO nightglow brightness. Dashed lines indicate the latitude region between $73^{\circ} \mathrm{S}$ and $44^{\circ} \mathrm{S}$ selected for wave analysis in $8 \mathrm{~d}$. This range captures the bulk of the observed variability while minimizing the influence from other mid-latitude features.

Figure 8c. Same as figure 8b, but for the LMD model simulations sampled to match the data. The model matches adequately at longitudes around $120^{\circ}$, but exhibits a second feature around $-60^{\circ}$ that was not observed.

Figure 8d. Local-time zonal mean variation of the southern polar NO nightglow brightness averaged between $73^{\circ} \mathrm{S}$ and $44^{\circ} \mathrm{S}$ latitude. Each curve shows 3-hour averages. 


\section{Conclusions and future work}

IUVS nitric oxide nightglow disk images are an unanticipated bonus of the MAVEN mission. They are unique among Mars datasets in providing good coverage in latitude, longitude, local time and season (solar longitude). This four-dimensional coverage removes biases and ambiguities inherent in observations fixed in local time (as many orbiters) or latitude and longitude (specifically landed assets). The images have proven to be a powerful tool for the identification of atmospheric downwelling regions and their modulation by waves and tides. Furthermore, they highlight seasonal transitions in circulation patterns. The observed effects are of such large amplitude and high signal-to-noise ratio that subsequent analyses could subdivide the dataset more finely than attempted in this synoptic approach.

The dataset presented here, by virtue of this extensive coverage, offers the most complete observations to date bearing on mesospheric circulation and tides. The main results can be succinctly stated as seasonal changes in latitudinal structure modulated by tides in longitude and local time: During the equinoxes, an emission peak due to equatorial downwelling forms with very strong DE2 tidal modulation. Polar brightenings occur throughout much of the year and are strongest around the winter solstices. They are caused by downwelling from the thermosphere and subsequent horizontal transport to the nightside; the polar emissions are further modulated by waves that differ between north and south poles. These top-level results stand alone for their direct insights into the mesosphere, though more important implications will come when integrated with our understanding of circulation, waves, and tides in the troposphere below and thermosphere above. In particular, future analyses should examine the connections in circulation patterns between these layers and the propagation of tides from the bottom to the top of the atmosphere. Together, these should allow advances in understanding the mechanisms behind these phenomena.

The LMD-MGCM matches most features of the observations with remarkable accuracy. The match is especially significant because the model did not require any tuning or optimization based on the observations. A good match to polar winter enhancements was expected after the comparison in Stiepen17, though their lack of data poleward of $\pm 70^{\circ}$ latitude prevented as complete an analysis as here. Similarly, the equatorial equinox enhancements were present in both observations and models presented in Stiepen17, so the good match presented here is consistent. The good match in tidal modes presented here is a new result, and the quality of agreement is arguably better than would be expected without tuning of the model. This is especially true for the match to the geographic location of the $\left(0^{\circ}, 0^{\circ}\right)$ spot. A closer look at the underlying physics in the model behind the polar enhancements should be undertaken in the future.

Despite the overall good match by the LMD-MGCM, several significant data/model discrepancies stand out and offer opportunities for model improvements. First, the observed global average nightglow intensity is higher than the model value by a factor of 1.9 . The model either underestimates the creation of atomic $\mathrm{N}$ and $\mathrm{O}$, or overestimates their loss through nonradiative paths. In either case, there are likely to be ramifications for other aspects of atmospheric chemistry once the model matches the observed brightnesses. Since the largest mismatches occur well away from the poles, a search for mechanisms to boost emission there in the model will be needed. Second, the model fails to match the local time behavior of the strongest tide feature observed, the $\left(0^{\circ}, 0^{\circ}\right)$ spot associated with the DE2 tide. The spot peaks well before midnight in the observations and well after midnight in the model. Our model run 
examination offers the possibility that predicting emission too low in altitude shifts the peak too late in the night. Alternatively, the implementation of diurnal tides in the relevant altitude range may be incorrect, not being constrained by any other observations. Since prior IUVS results on NO nightglow altitude profiles found that the model predicts emission too high, the error in diurnal tides seems more plausible. Finally, the observed south polar wave structure is not well matched by the LMD-MGCM. The model mechanism driving the second longitudinal maximum around $-60^{\circ}$ needs to be identified, and reasons for its overestimation investigated. It may be that higher model resolution, as used in Pottier et al. (2017) will be useful.

We have presented here only the top-level conclusions from IUVS observations using heavily averaged data, so many paths present themselves for deeper analysis. First, the wave and tide analysis should be greatly expanded through detailed harmonic analysis of the wave structures including tidal decomposition and Hovmöller analyses. Similar approaches could search for ultra-fast Kelvin waves; such waves with periods more than one sol are suppressed by the methods used in this work. Second, much can be learned from a study of the day-to-day variability of NO nightglow images. In polar regions, a search should be carried out for Rossby waves comparable to those seen in ozone distributions lying tens of kilometers below. The high frequency of IUVS images could also help precisely quantify the impact of changes in solar activity on the NO nightglow emission and a GCM could be coupled to observations to track back the emission to the production rates of $\mathrm{N}$ and $\mathrm{O}$ in the dayside and their transport to the nightside. This would benefit from IUVS observations over larger variations of solar activities. The higher-level data products used in this paper would be suitable for all these studies, and are made available to the community as described the following section.

\section{Acknowledgments and Data Availability}

The MAVEN mission is supported by NASA through the Mars Exploration Program in association with the University of Colorado and NASA's Goddard Space Flight Center. IUVS level 1B data (spatially-resolved spectra) are available in the Planetary Data System (PDS), labeled v13_r02 tagged with "apoapse" at https://pdsatmospheres.nmsu.edu/data and services/atmospheres_data/MAVEN/maven iuvs.html. This work used high-level data products (MLR brightnesses derived from PDS products) which will be archived in the FAIR-compliant CU Scholar Repository (https://doi.org/10.25810/fke8-7z93). The LMD-MGCM model results used in this paper are also available at the CU Scholar Repository, and questions may be addressed to ggalindo@iaa.es. A. Stiepen was supported by the Fund for Scientific Research (F.R.S.-FNRS). J.-C. Gérard acknowledges support from the PRODEX program of the Belgian Federal Science Policy Office, managed by ESA. F.GonzalezGalindo was funded by the Spanish Ministry of Science, Innovation, and Universities, the Spanish State Agency for Research and by EC FEDER funds under grants ESP2017-87143-R and RTI2018-100920-J-I00 and through the "Center of Excellence Severo Ochoa" award to the Instituto de Astrofísica de Andalucía (SEV-2017-0709)" 


\section{References}

782

783

784

785

786

787

788

789

790

791

792

793

794

795

796

797

798

799

800

801

802

803

804

805

806

807

808

809

810

811

812

813

814

Angelats i Coll, M. (2004). Upper atmosphere of Mars up to $120 \mathrm{~km}$ : Mars Global Surveyor accelerometer data analysis with the LMD general circulation model. Journal of Geophysical Research, 109(E1). doi: 10.1029/2003je002163

Banfield, D., Conrath, B. J., Smith, M. D., Christensen, P. R., \& Wilson, R. J. (2003). Forced waves in the martian atmosphere from MGS TES nadir data. Icarus, 161(2), 319-345. doi: 10.1016/s0019-1035(02)00044-1

Banfield, D., Conrath, B. J., Gierasch, P. J., Wilson, R. J., \& Smith, M. D. (2004). Traveling waves in the martian atmosphere from MGS TES Nadir data. Icarus, 170(2), 365-403. doi: $10.1016 /$ j.icarus.2004.03.015

Barnes, J. R., Haberle, R. M., Pollack, J. B., Lee, H., \& Schaeffer, J. (1996). Mars atmospheric dynamics as simulated by the NASA Ames general circulation model: 3 . Winter quasistationary eddies. Journal of Geophysical Research: Planets, 101(E5), 12753-12776. doi: 10.1029/96je00179

Barnes, J.R. (2003). Mars Weather Systems and Maps: FFSM Analyses of MGS TES Temperature Data. Sixth International Conference on Mars, July 20-25 2003, Pasadena, California, abstract no. 3127

Bell, J.M., S.W. Bougher, J.R. Murphy (2007). Vertical dust mixing and the interannual variations in the Mars thermosphere. Journal of Geophysical Research: 112 (E12), doi: 10.1029/2006JE002856

Bertaux, J.-L., Leblanc, F., Perrier, S., Quemerais, E., Korablev, O., Dimarellis, E., ... Sandel, B. (2005). Nightglow in the Upper Atmosphere of Mars and Implications for Atmospheric Transport. Science, 307(5709), 566-569. doi: 10.1126/science.1106957

Bertaux, J.-L., Korablev, O., Perrier, S., Quémerais, E., Montmessin, F., Leblanc, F., ... Guibert, S. (2006). SPICAM on Mars Express: Observing modes and overview of UV spectrometer data and scientific results. Journal of Geophysical Research, 111(E10). doi: $10.1029 / 2006 \mathrm{je} 002690$

Bertaux, J. L., Gondet, B. P., Lefèvre, F. undefined, Bibring, J. undefined, \& Montmessin, F. undefined. (2012). First detection of O $21.27 \mu \mathrm{m}$ nightglow emission at Mars with OMEGA/MEX and comparison with general circulation model predictions. Journal of Geophysical Research: Planets, 117(E11). doi: 10.1029/2011je003890

Bougher, S. W., Gérard, J. C., Stewart, A. I. F., \& Fesen, C. G. (1990). The Venus nitric oxide night airglow: Model calculations based on the Venus thermospheric general circulation model. Journal of Geophysical Research, 95(A5), 6271. doi: 10.1029/ja095ia05p06271 
Bougher, S. W., Engel, S., Hinson, D. P., \& Murphy, J. R. (2004). MGS Radio Science electron density profiles: Interannual variability and implications for the Martian neutral atmosphere. Journal of Geophysical Research, 109(E3). doi: 10.1029/2003je002154

Bougher, S. W., Rafkin, S., \& Drossart, P. (2006). Dynamics of the Venus upper atmosphere: Outstanding problems and new constraints expected from Venus Express. Planetary and Space Science, 54(13-14), 1371-1380. doi: 10.1016/j.pss.2006.04.023

Bougher, S. W., Pawlowski, D., Bell, J. M., Nelli, S., Mcdunn, T., Murphy, J. R., ... Ridley, A. (2015). Mars Global Ionosphere-Thermosphere Model: Solar cycle, seasonal, and diurnal variations of the Mars upper atmosphere. Journal of Geophysical Research: Planets, 120(2), 311-342. doi: 10.1002/2014je004715

Bougher, S. W., D. A. Brain, J. L. Fox, F. Gonzalez-Galindo, C. Simon-Wedlund, and P. G. Withers (2017). Chapter 14: Upper Neutral Atmosphere and Ionosphere, in The Atmosphere and Climate of Mars, ed. B. Haberle, M. Smith, T. Clancy, F. Forget, R. Zurek, Cambridge University Press, doi:10.1017/9781107016187

Brecht, A. S., Bougher, S. W., Gérard, J.-C., Parkinson, C. D., Rafkin, S., \& Foster, B. (2011). Understanding the variability of nightside temperatures, NO UV and O2IR nightglow emissions in the Venus upper atmosphere. Journal of Geophysical Research, 116(E8). doi: $10.1029 / 2010 \mathrm{je} 003770$

Brecht, A. S., S. W. Bougher, E. Yigit, H.-L. Liu (2019). Understanding the Impact of Waves on Venus' Upper Atmosphere through General Circulation Model Simulations, International Venus Conference 2019, $74^{\text {th }}$ Fujihara Seminar, abstract, Hokkaido, Japan, 31-May to 3June 2019.

Clancy, R. T., Sandor, B. J., Wolff, M. J., Smith, M. D., Lefèvre, F., Madeleine, J.-B., ... Heavens, N. (2012). Extensive MRO CRISM observations of 1.27 $\mu \mathrm{m}$ O2airglow in Mars polar night and their comparison to MRO MCS temperature profiles and LMD GCM simulations. Journal of Geophysical Research: Planets, 117(E11). doi: $10.1029 / 2011 \mathrm{je} 004018$

Clancy, R. T., Sandor, B. J., Wolff, M. J., Smith, M. D., Lefèvre, F., Madeleine, J.-B., ... Heavens, N. (2013a). Correction to "Extensive MRO CRISM observations of $1.27 \mu \mathrm{m}$ O2airglow in Mars polar night and their comparison to MRO MCS temperature profiles and LMD GCM simulations." Journal of Geophysical Research: Planets, 118(5), 11481154. doi: 10.1002/jgre.20073

Clancy, R. T., Sandor, B. J., García-Muñoz, A., Lefèvre, F., Smith, M. D., Wolff, M. J., ... Nair, H. (2013b). First detection of Mars atmospheric hydroxyl: CRISM Near-IR measurement versus LMD GCM simulation of OH Meinel band emission in the Mars polar winter atmosphere. Icarus, 226(1), 272-281. doi: 10.1016/j.icarus.2013.05.035 
Clancy, R. T., Wolff, M. J., Lefèvre, F., Cantor, B. A., Malin, M. C., \& Smith, M. D. (2016). Daily global mapping of Mars ozone column abundances with MARCI UV band imaging. Icarus, 266, 112-133. doi: 10.1016/j.icarus.2015.11.016

Cox, C., Saglam, A., Gérard, J.-C., Bertaux, J.-L., González-Galindo, F., Leblanc, F., \& Reberac, A. (2008). Distribution of the ultraviolet nitric oxide Martian night airglow: Observations from Mars Express and comparisons with a one-dimensional model. Journal of Geophysical Research, 113(E8). doi: 10.1029/2007je003037

Eastes, R.W., R.E Huffman, F.J. Leblanc (1992). $\mathrm{NO}$ and $\mathrm{O}_{2}$ ultraviolet nightglow and spacecraft glow from the S3-4 satellite. Planetary and Space Science, 40, 481-493. doi: 10.1016/0032-0633(92)90168-N

Elrod, M. K., S. W. Bougher, J. M. Bell, P. R. Mahaffy, M. Benna, S. Stone, R. Yelle, and B. M. Jakosky (2017). He bulge revealed: $\mathrm{He}$ and $\mathrm{CO}_{2}$ diurnal and seasonal variations in the upper atmosphere of Mars as detected by MAVEN NGIMS, J. Geophys. Res. Space Physics, 122, 2564-2573. doi:10.1002/2016JA023482

England, S. L., Liu, G., Withers, P., Yiğit, E., Lo, D., Jain, S., ... Jakosky, B. M. (2016). Simultaneous observations of atmospheric tides from combined in situ and remote observations at Mars from the MAVEN spacecraft. Journal of Geophysical Research: Planets, 121(4), 594-607. doi: 10.1002/2016je004997

England, S. L., Liu, G., Kumar, A., Mahaffy, P. R., Elrod, M., Benna, M., et al. (2019). Atmospheric tides at high latitudes in the Martian upper atmosphere observed by MAVEN and MRO. Journal of Geophysical Research: Space Physics, 124, 2943-2953. doi.org/10.1029/2019JA026601

Eparvier, F., P. Chamberlin, T. Woods, and E. Thiemann (2015), The solar extreme ultraviolet monitor for MAVEN, Space Sci. Rev., 195( 1-4), 293-301.

Fedorova, A. A., Lefèvre, F., Guslyakova, S., Korablev, O., Bertaux, J.-L., Montmessin, F., ... Gondet, B. (2012). The $\mathrm{O} 2$ nightglow in the Martian atmosphere by SPICAM onboard of Mars-Express. Icarus, 219(2), 596-608. doi: 10.1016/j.icarus.2012.03.031

Forbes, J. M., Bridger, A. F. C., Bougher, S. W., Hagan, M. E., Hollingsworth, J. L., Keating, G. M., \& Murphy, J. (2002). Nonmigrating tides in the thermosphere of Mars. Journal of Geophysical Research: Planets, 107(E11). doi: 10.1029/2001je001582

Forget, F., F. Hourdin, R. Fournier, C. Hourdin, O. Talagrand, M. Collins, S. R. Lewis, P. L. Read, and J.-P. Huot (1999), Improved general circulation models of the Martian atmosphere from the surface to above $80 \mathrm{~km}$, J. Geophys. Res., 104, 24,155-24,176. doi: 10.1029/1999JE001025 
885
Gagné, M.-È., Melo, S. M. L., Lefèvre, F., González-Galindo, F., \& Strong, K. (2012). Modeled $\mathrm{O}_{2}$ airglow distributions in the Martian atmosphere. Journal of Geophysical Research: Planets, 117(E6). doi: 10.1029/2011je003901

Gagné, M.-Ė., Bertaux, J.-L., González-Galindo, F., Melo, S. M. L., Montmessin, F., \& Strong, K. (2013). New nitric oxide (NO) nightglow measurements with SPICAM/MEx as a tracer of Mars upper atmosphere circulation and comparison with LMD-MGCM model prediction: Evidence for asymmetric hemispheres. Journal of Geophysical Research: Planets, 118(10), 2172-2179. doi: 10.1002/jgre.20165

Gérard, J.-C., Bougher, S. A., López-Valverde, M., Pätzold, M., Drossart, P., \& Piccioni, G. (2017). Aeronomy of the Venus Upper Atmosphere. Space Science Reviews, 212(3-4), 1617-1683. doi: 10.1007/s11214-017-0422-0

Gilli, G., Forget, F., Spiga, A., Navarro, T., Montabone, L., Millour, E. (2020). Impact of gravity waves on the middle atmosphere of Mars: a non-orographic gravity wave parameterization based on Global Climate modeling and MCS observations, accepted in J. Geophys. Res. Doi: 10.1029/2018JE005873

González-Galindo, F., Forget, F., López-Valverde, M. A., Angelats i Coll, M., \& Millour, E. (2009). A ground-to-exosphere Martian general circulation model: 1. Seasonal, diurnal, and solar cycle variation of thermospheric temperatures. Journal of Geophysical Research, 114(E4). doi: 10.1029/2008je003246

González-Galindo, F., López-Valverde, M. A., Forget, F., García-Comas, M., Millour, E., \& Montabone, L. (2015). Variability of the Martian thermosphere during eight Martian years as simulated by a ground-to-exosphere global circulation model. Journal of Geophysical Research: Planets, 120(11), 2020-2035. doi: 10.1002/2015je004925

Gröller, H., Montmessin, F., Yelle, R. V., Lefèvre, F., Forget, F., Schneider, N. M., et al. (2018). MAVEN/IUVS stellar occultation measurements of Mars atmospheric structure and composition. Journal of Geophysical Research: Planets, 123, 1449-1483. doi: 10.1029/2017JE005466

Guzewich, S. D., Talaat, E. R., \& Waugh, D. W. (2012). Observations of planetary waves and nonmigrating tides by the Mars Climate Sounder. Journal of Geophysical Research: Planets, 117(E3). doi: 10.1029/2011je003924

Hess, S. L., Henry, R. M., Leovy, C. B., Ryan, J. A., \& Tillman, J. E. (1977). Meteorological results from the surface of Mars: Viking 1 and 2. Journal of Geophysical Research, 82(28), 4559-4574. doi: 10.1029/js082i028p04559

Hinson, D. P. (2006). Radio occultation measurements of transient eddies in the northern hemisphere of Mars. Journal of Geophysical Research, 111(E5). doi: $10.1029 / 2005 \mathrm{je} 002612$ 
Jakosky, B. M., R. P. Lin, J. M. Grebowsky, J. G. Luhmann, D. F. Mitchell, G. Beutelschies, ... R. Zurek (2015). The Mars Atmosphere and Volatile Evolution (MAVEN) Mission. Space Science Reviews, 195(1-4), 3-48. doi: 10.1007/s11214-015-0139-x

Keating, G. M., Bougher, S. W., Zurek, R. W., Tolson, R. H., Cancro, G. J., Noll, S. N., ... Babicke, J. M. (1998). The Structure of the Upper Atmosphere of Mars: In Situ Accelerometer Measurements from Mars Global Surveyor. Science, 279(5357), 16721676. doi: $10.1126 /$ science. 279.5357 .1672

Lee, C., et al. (2009), Thermal tides in the Martian middle atmosphere as seen by the Mars Climate Sounder, J. Geophys. Res., 114, E03005, doi:10.1029/2008JE003285.

Lewis, S. R., Mulholland, D. P., Read, P. L., Montabone, L., Wilson, R. J., \& Smith, M. D. (2016). The solsticial pause on Mars: 1. A planetary wave reanalysis. Icarus, 264, 456464. doi: 10.1016/j.icarus.2015.08.039

Lo, D. Y., Yelle, R. V., Schneider, N. M., Jain, S. K., Stewart, A. I. F., England, S. L., ... Jakosky, B. M. (2015). Nonmigrating tides in the Martian atmosphere as observed by MAVEN IUVS. Geophysical Research Letters, 42(21), 9057-9063. doi: $10.1002 / 2015 \mathrm{~g} 1066268$

McClintock, W. E., Schneider, N. M., Holsclaw, G. M., Clarke, J. T., Hoskins, A. C., Stewart, I. V., ... Deighan, J. (2015). The Imaging Ultraviolet Spectrograph (IUVS) for the MAVEN Mission. Space Science Reviews, 195(1-4), 75-124. doi: 10.1007/s11214-0140098-7

Medvedev, A. S., Yiğit, E., Hartogh, P., \& Becker, E. (2011). Influence of gravity waves on the Martian atmosphere: General circulation modeling. Journal of Geophysical Research, 116(E10). doi: 10.1029/2011je003848

Medvedev, A. S., et al. (2016), Comparison of the Martian thermospheric density and temperature from IUVS/MAVEN data and general circulation modeling, Geophys. Res. Lett., 43, 3095-3104, doi:10.1002/2016GL068388.

Millour et al. (2018). Exploring the interannual variability of the Martian atmosphere with the Mars Climate Database v5.3. 42nd COSPAR Scientific Assembly, C4.3-6-18.

Montabone, L., Forget, F., Millour, E., Wilson, R. J., Lewis, S. R., Cantor, B., et al. (2015). Eight-year climatology of dust optical depth on Mars. Icarus, 251, 65-95. https://doi.org/10.1016/j.icarus.2014.12.034

Montmessin, F., Forget, F., Rannou, P., Cabane, M., \& Haberle, R. M. (2004). Origin and role of water ice clouds in the Martian water cycle as inferred from a general circulation model. Journal of Geophysical Research, 109(E10). doi: 10.1029/2004je002284 
956

957

958

959

960

961

962

963

964

965

966

967

968

969

970

971

972

973

974

975

976

977

978

979

980

981

982

983

984

985

986

987

988

Moudden, Y. and J. M. Forbes (2008). Effects of vertically propagating thermal tides on the mean structure and dynamics of Mars' lower thermosphere. Geophysical Research Letters, 35, L23805, doi:10.1029/2008GL036086

Pottier, A., Forget, F., Montmessin, F., Navarro, T., Spiga, A., Millour, E., ... Madeleine, J.-B. (2017). Unraveling the Martian water cycle with high-resolution global climate simulations. Icarus, 291, 82-106. doi: 10.1016/j.icarus.2017.02.016

Royer, E., Montmessin, F., \& Bertaux, J.-L. (2010). NO emissions as observed by SPICAV during stellar occultations. Planetary and Space Science, 58(10), 1314-1326. doi: 10.1016/j.pss.2010.05.015

Royer, E. M., Montmessin, F., \& Marcq, E. (2016). Variability of the nitric oxide nightglow at Venus during solar minimum. Journal of Geophysical Research: Planets, 121(5), 846853. doi: $10.1002 / 2016 \mathrm{je} 005013$

Schneider, N. M., Deighan, J. I., Jain, S. K., Stiepen, A., Stewart, A. I. F., Larson, D., ... Jakosky, B. M. (2015). Discovery of diffuse aurora on Mars. Science, 350(6261). doi: $10.1126 /$ science.aad0313

Schneider, N. M., Jain, S. K., Deighan, J., Nasr, C. R., Brain, D. A., Larson, D., et al. (2018). Global aurora on Mars during the September 2017 space weather event. Geophysical Research Letters, 45, 7391-7398. https://doi.org/10.1029/ 2018GL077772

Smith, F. L., \& Smith, C. (1972). Numerical evaluation of Chapman's grazing incidence integral $\mathrm{Ch}(\mathrm{X}, \chi)$. Journal of Geophysical Research, 77(19), 3592-3597. doi: 10.1029/JA077i019p03592

Stevens, M. H., Evans, J. S., Schneider, N. M., Stewart, A. I. F., Deighan, J., Jain, S. K., ... Jakosky, B. M. (2015). New observations of molecular nitrogen in the Martian upper atmosphere by IUVS on MAVEN. Geophysical Research Letters, 42(21), 9050-9056. doi: $10.1002 / 2015 \mathrm{~g} 1065319$

Stevens, M. H., Siskind, D. E., Evans, J. S., Fox, J. L., Deighan, J., Jain, S. K., \& Schneider, N. M. (2019). Detection of the nitric oxide dayglow on Mars by MAVEN/IUVS. Journal of Geophysical Research: Planets, 124. https://doi.org/10.1029/2019JE005945

Stewart, A. I., \& Barth, C. A. (1979). Ultraviolet Night Airglow of Venus. Science, 205(4401), 59-62. doi: 10.1126/science.205.4401.59

Stewart, A. I. F., Gérard, J.-C., Rusch, D. W., \& Bougher, S. W. (1980). Morphology of the Venus ultraviolet night airglow. Journal of Geophysical Research, 85(A13), 7861-7870. doi: 10.1029/ja085ia13p07861 
Stiepen, A., Soret, L., Gérard, J.-C., Cox, C., \& Bertaux, J.-L. (2012). The vertical distribution of the Venus NO nightglow: Limb profiles inversion and one-dimensional modeling. Icarus, 220(2), 981-989. doi: 10.1016/j.icarus.2012.06.029

Stiepen, A., Gérard, J.-C., Dumont, M., Cox, C., \& Bertaux, J.-L. (2013). Venus nitric oxide nightglow mapping from SPICAV nadir observations. Icarus, 226(1), 428-436. doi: 10.1016/j.icarus.2013.05.031

Stiepen, A., Gérard, J.-C., Gagné, M.-È., Montmessin, F., \& Bertaux, J.-L. (2015). Ten years of Martian nitric oxide nightglow observations. Geophysical Research Letters, 42(3), 720725. doi: $10.1002 / 2014 \mathrm{~g} 1062300$

Stiepen, A., Jain, S. K., Schneider, N. M., Deighan, J. I., González-Galindo, F., Gérard, J.-C., ... Jakosky, B. M. (2017). Nitric oxide nightglow and Martian mesospheric circulation from MAVEN/IUVS observations and LMD-MGCM predictions. Journal of Geophysical Research: Space Physics, 122(5), 5782-5797. doi: 10.1002/2016ja023523

Tennyson P. D., P.D. Feldman, P. D. G.F. Hartig, R.C. Henry (1986). Journal of Geophysical Research, 91, 12291, 10141-10146. doi: 10.1029/JA091iA09p10141

Wilson, R. J., \& Hamilton, K. (1996). Comprehensive Model Simulation of Thermal Tides in the Martian Atmosphere. Journal of the Atmospheric Sciences, 53(9), 1290-1326. doi: 10.1175/1520-0469(1996)053<1290:cmsott>2.0.co;2

Wilson, R. J. (2000). Evidence for Diurnal Period Kelvin Waves in the Martian Atmosphere from Mars Global Surveyor TES Data. Geophysical Research Letters, 27(23). doi: 10.1029/2000GL012028

Wilson, R. J. (2002). Evidence for nonmigrating thermal tides in the Mars upper atmosphere from the Mars Global Surveyor Accelerometer Experiment. Geophysical Research Letters, 29(7). doi: 10.1029/2001g1013975

Withers, P., Bougher, S. W., \& Keating, G. M. (2003). The effects of topographically-controlled thermal tides in the martian upper atmosphere as seen by the MGS accelerometer. Icarus, 164(1), 14-32. doi: 10.1016/s0019-1035(03)00135-0

Withers, P., Pratt, R., Bertaux, J.-L., \& Montmessin, F. (2011). Observations of thermal tides in the middle atmosphere of Mars by the SPICAM instrument. Journal of Geophysical Research, 116, E11005. https://doi.org/10.1029/2011JE003847 
Figure 1. 


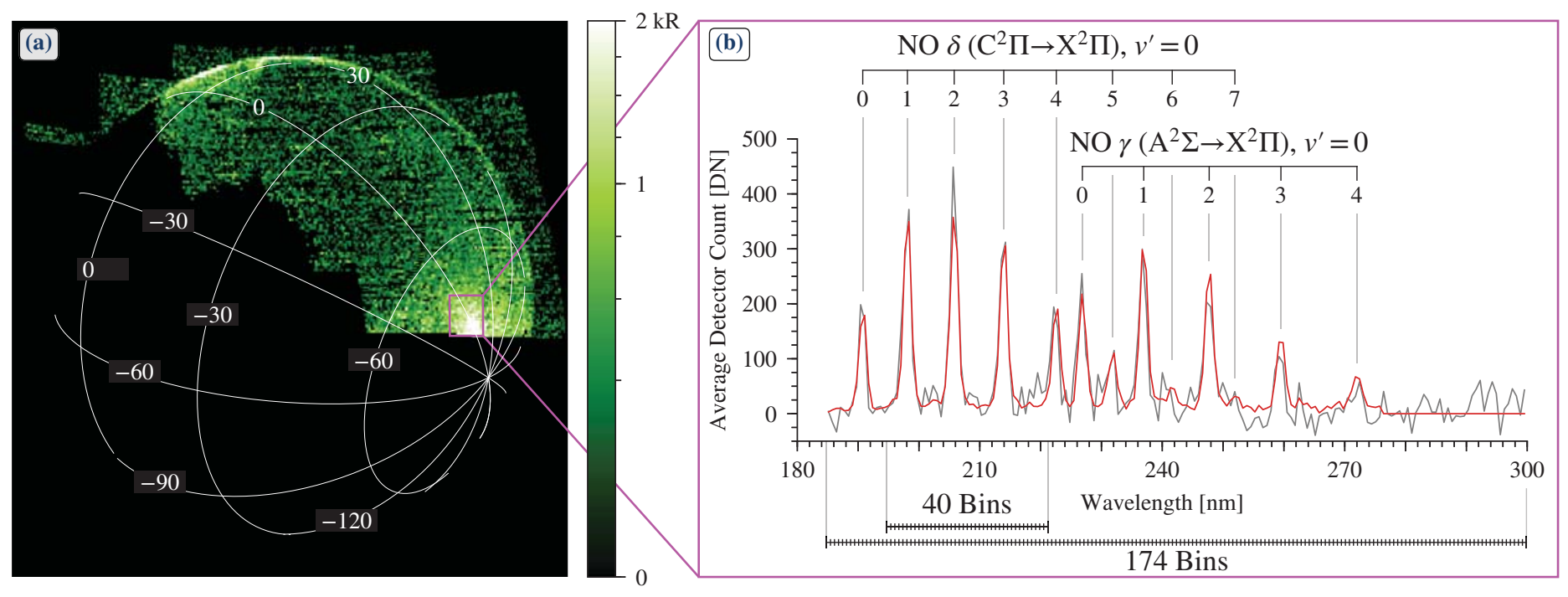


Figure 2. 

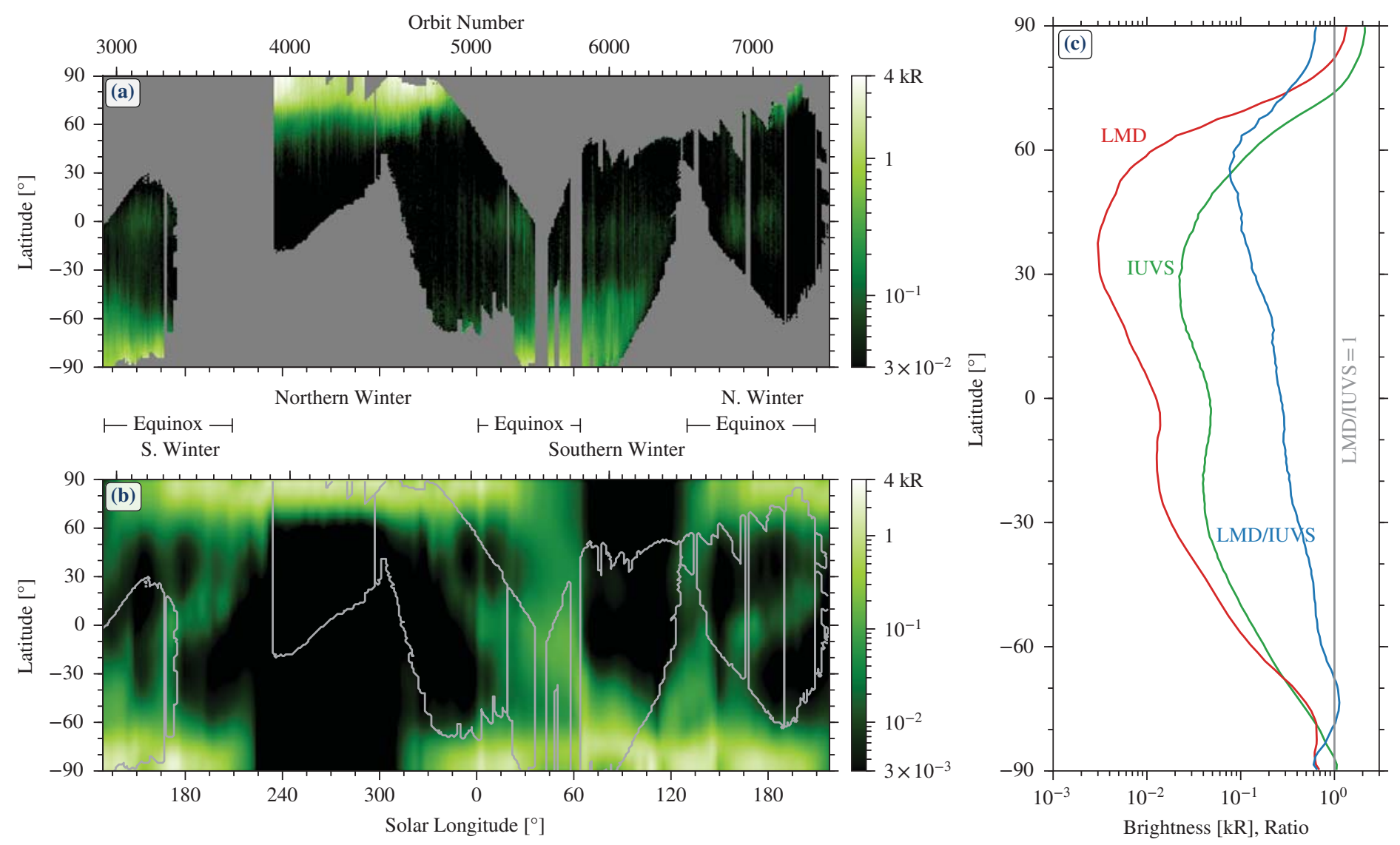
Figure 3. 


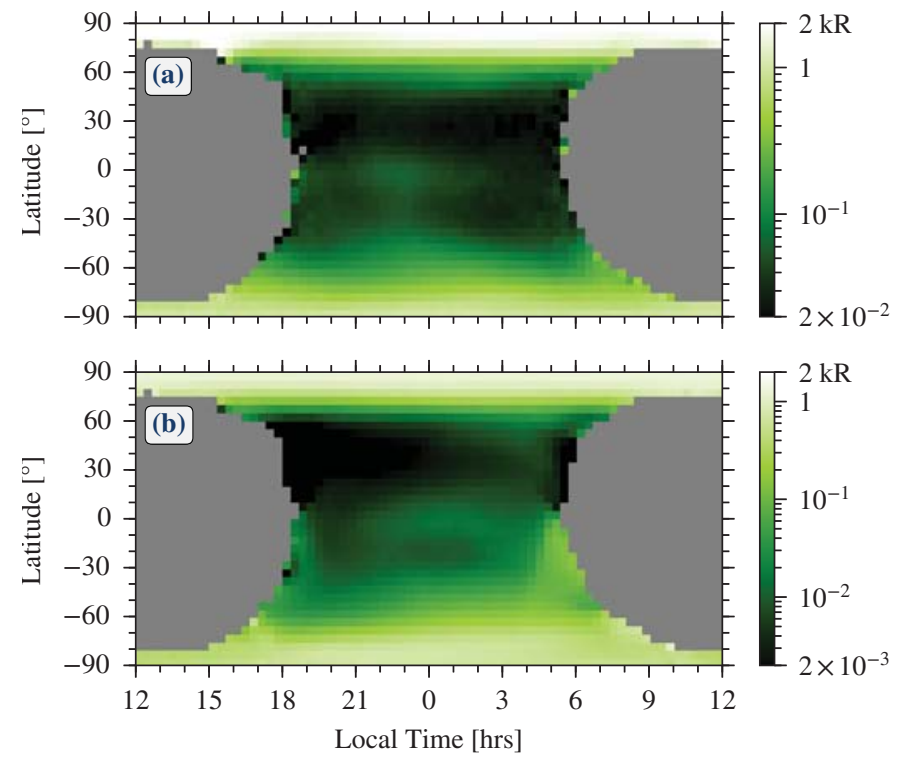


Figure 4. 

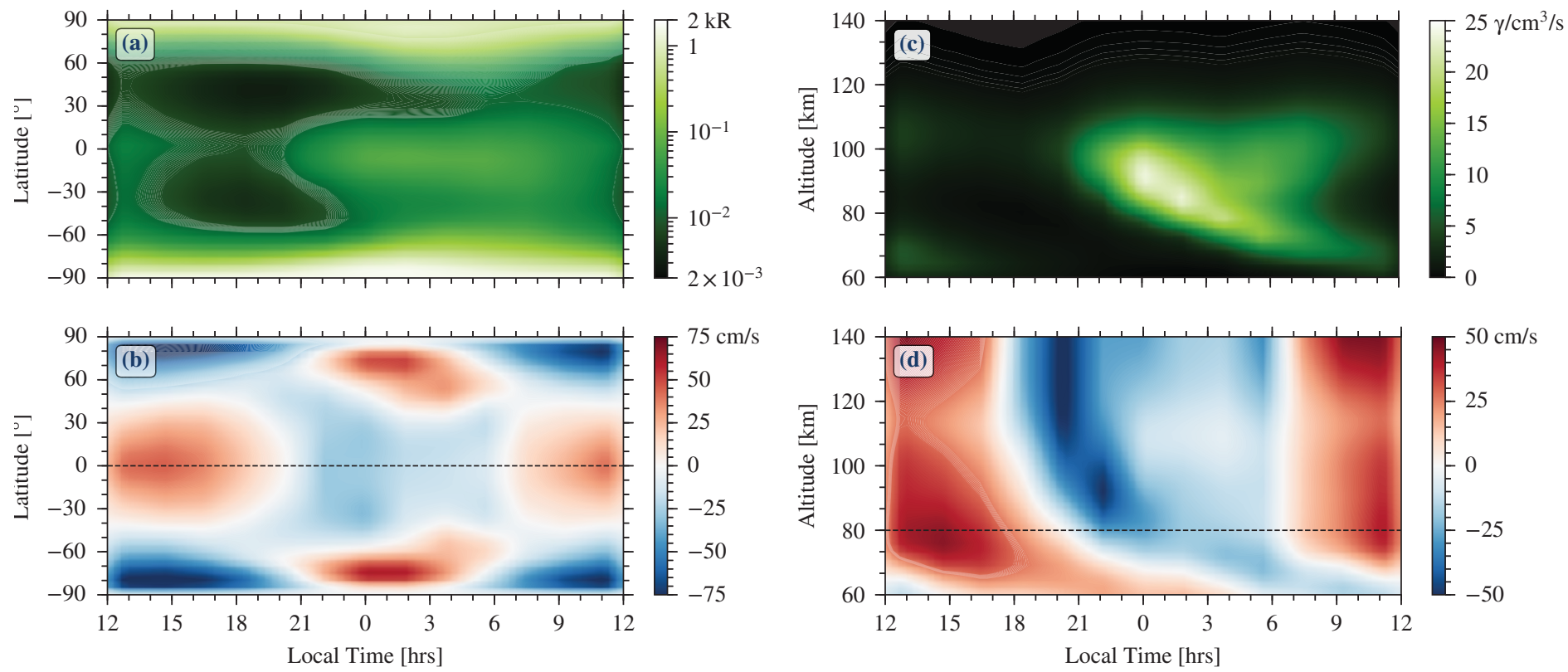
Figure 5. 

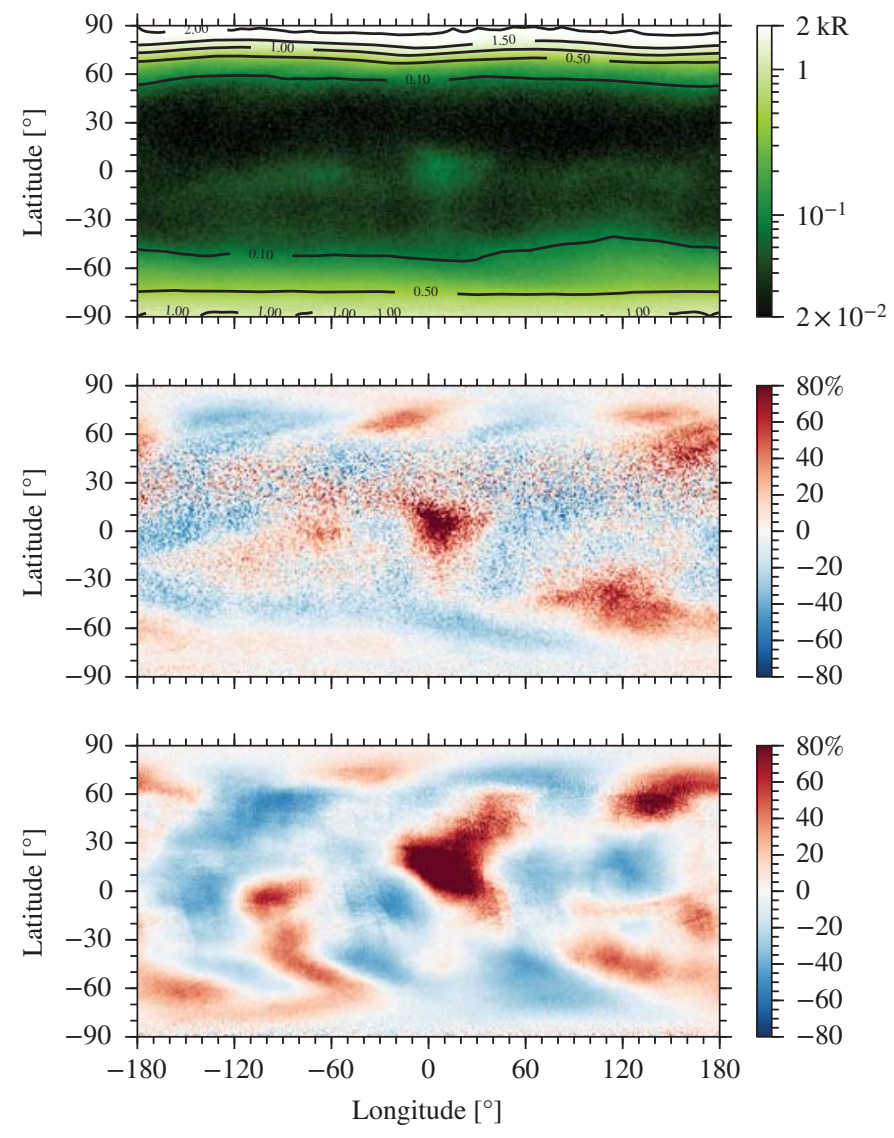
Figure 6. 

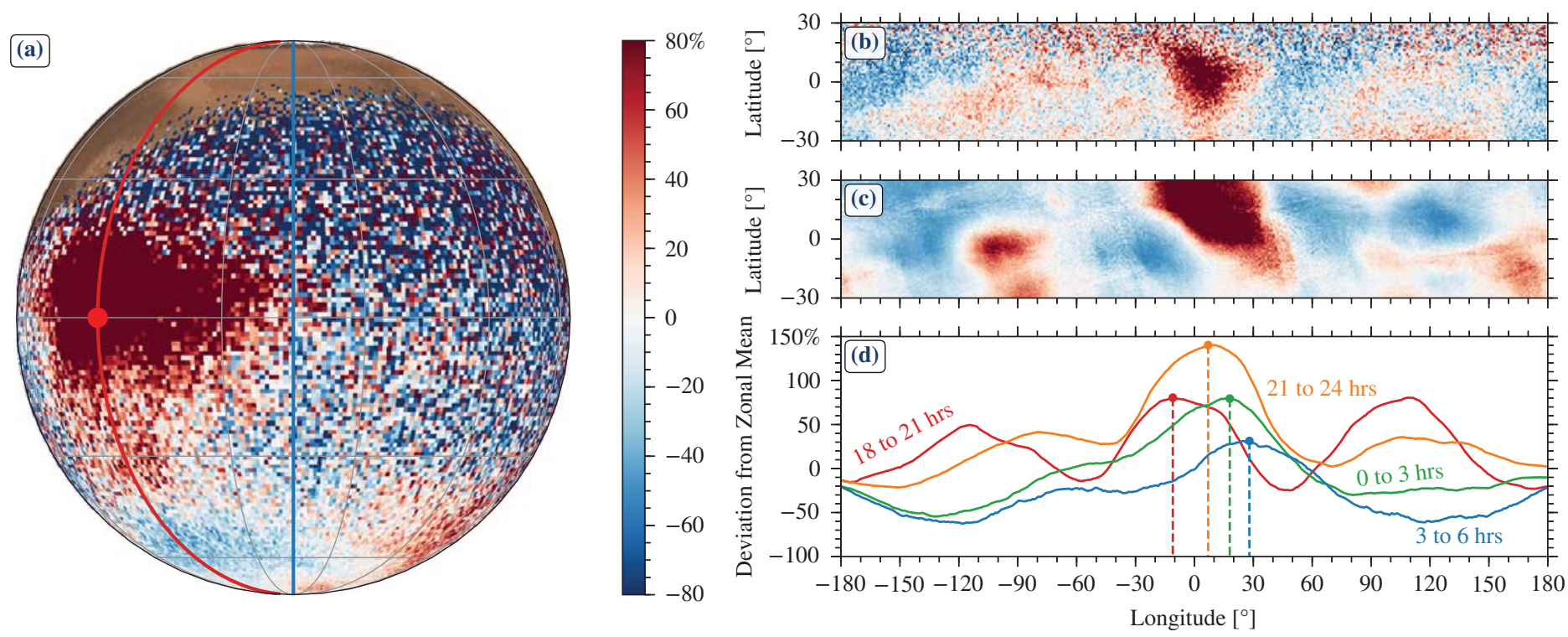
Figure 7. 


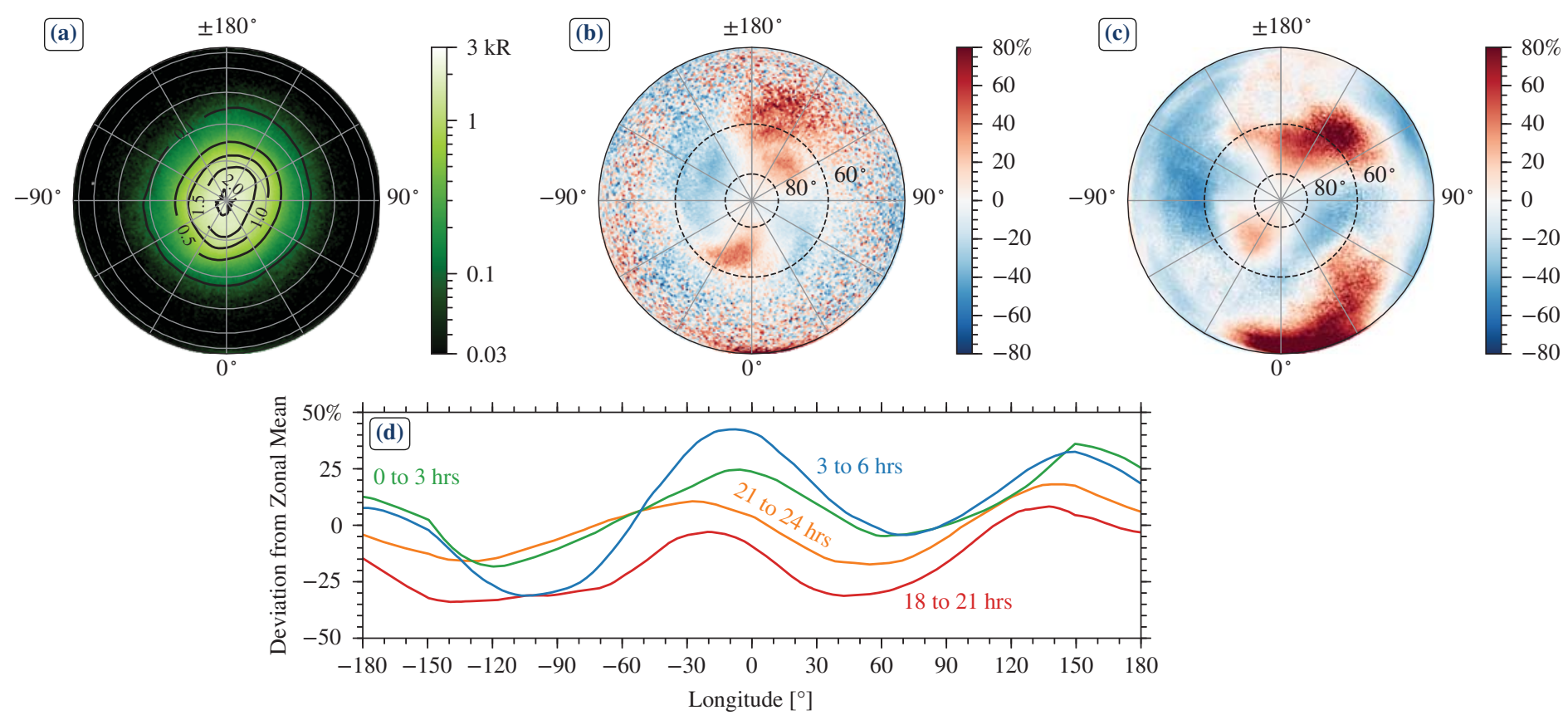


Figure 8. 


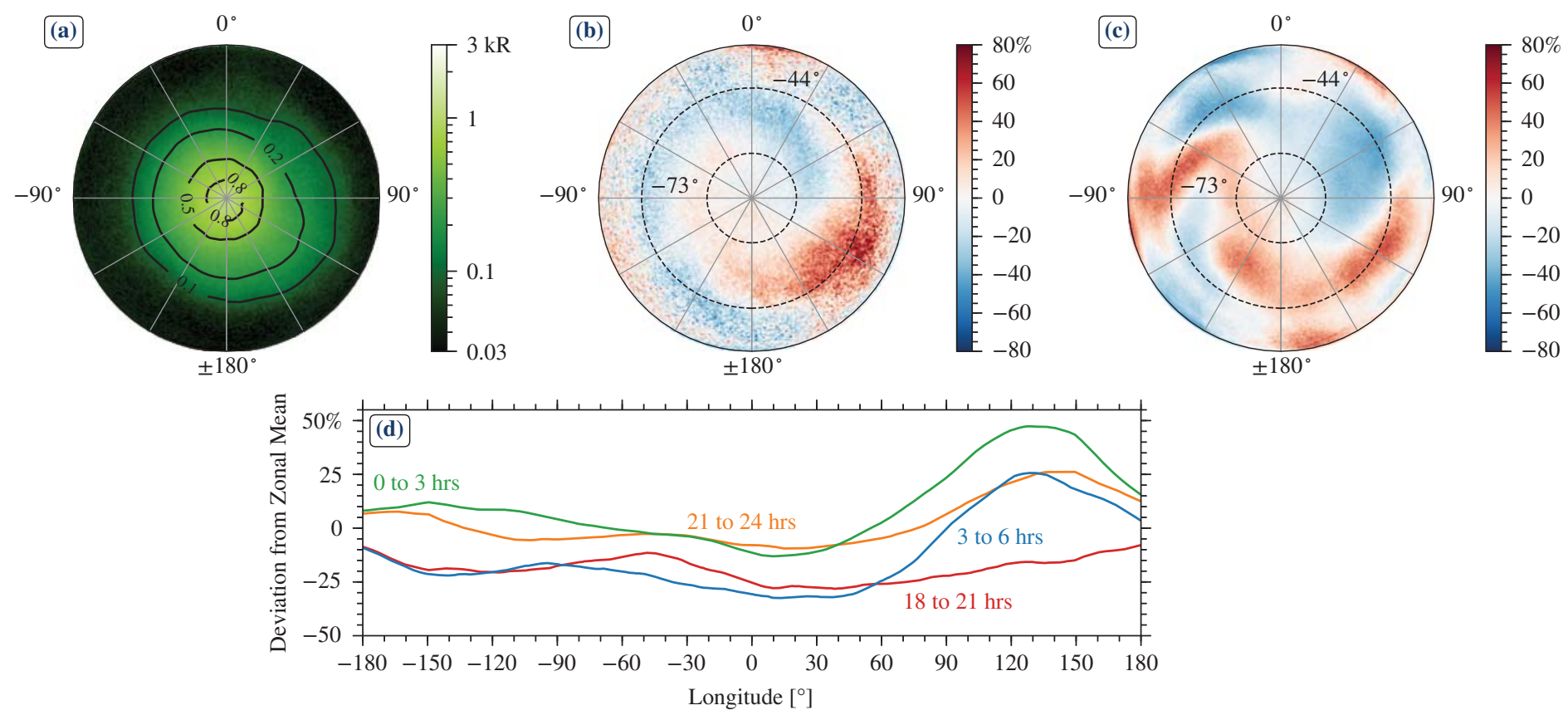

